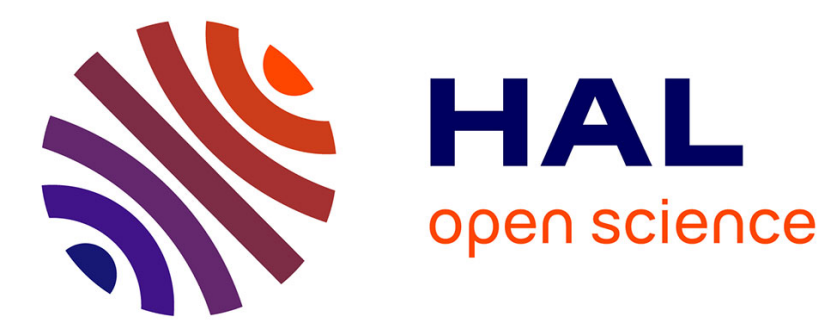

\title{
Ultrafast photoinduced flavin dynamics in the unusual active site of the tRNA methyltransferase TrmFO
}

Nadia Dozova, Fabien Lacombat, Charles Bou-Nader, Djemel Hamdane, Pascal Plaza

\section{- To cite this version:}

Nadia Dozova, Fabien Lacombat, Charles Bou-Nader, Djemel Hamdane, Pascal Plaza. Ultrafast photoinduced flavin dynamics in the unusual active site of the tRNA methyltransferase TrmFO. Physical Chemistry Chemical Physics, 2019, 21 (17), pp.8743-8756. 10.1039/C8CP06072J . hal-02095777

\section{HAL Id: hal-02095777 \\ https://hal.science/hal-02095777}

Submitted on 7 Dec 2020

HAL is a multi-disciplinary open access archive for the deposit and dissemination of scientific research documents, whether they are published or not. The documents may come from teaching and research institutions in France or abroad, or from public or private research centers.
L'archive ouverte pluridisciplinaire HAL, est destinée au dépôt et à la diffusion de documents scientifiques de niveau recherche, publiés ou non, émanant des établissements d'enseignement et de recherche français ou étrangers, des laboratoires publics ou privés. 
Ultrafast photoinduced flavin dynamics in the unusual active site of the tRNA methyltransferase TrmFO



a PASTEUR, Département de chimie, École normale supérieure, PSL University, Sorbonne Université, CNRS, 75005 Paris, France.

${ }^{b}$ Laboratoire de Chimie des Processus Biologiques, CNRS-UMR 8229, Collège de France, Sorbonne Université , 75005 Paris, France.

\section{ABSTRACT}

Flavoproteins often stabilize their flavin coenzyme by stacking interactions involving the isoalloxazine moiety of the flavin and an aromatic residue from the apoprotein. The bacterial FAD and folate-dependent tRNA methyltransferase TrmFO has the singularity of stabilizing its FAD coenzyme by an unusual $\mathrm{H}$-bond-assisted $\pi-\pi$ stacking interaction, involving a conserved tyrosine ( $\mathrm{Y}_{346}$ in Bacillus subtilis TrmFO, BsTrmFO), the isoalloxazine of FAD and the backbone of a catalytic cysteine $\left(C_{53}\right)$. Here, the interaction between $F A D$ and $Y_{346}$ is been investigated by measuring the photoinduced flavin dynamics of BsTrmFO, in the wild-type (WT) protein, C53A and several $\mathrm{Y}_{346}$ mutants by ultrafast transient absorption spectroscopy. In C53A, the excited FAD very rapidly ( 0.43 ps) abstracts an electron from $\mathrm{Y}_{346}$, yielding the $\mathrm{FAD}^{\circ-} / \mathrm{Y}_{346} \mathrm{OH}^{\bullet+}$ radical pair, while relaxation of the local environment (1.3 ps) of the excited flavin produces a slight Stokes shift of its stimulated emission band. The radical pair then decays via a charge recombination, mostly in 3-4 ps, without any deprotonation of $\mathrm{Y}_{346} \mathrm{OH}^{\bullet+}$ radical. Presumably, the $\mathrm{H}$-bond between $\mathrm{Y}_{346}$ and the amide group of $\mathrm{C}_{53}$ increases the pKa of $\mathrm{Y}_{346} \mathrm{OH}^{\bullet+}$ and slows down its deprotonation. The dynamics of WT BsTrmFO shows additional slow decay components ( 43 and 700 ps), absent in the C53A mutant, assigned to excited $F A D_{\text {ox }}$ populations not undergoing fast photoreduction. Their presence is likely due to a more flexible structure of WT protein, favored by the presence of $C_{53}$. Interestingly, mutations of $Y_{346}$ canceling its electron donating character lead to multiple slower quenching channels in the ps-ns regime. These channels are proposed to be due electron abstraction: (i) from the adenine moiety of $F A D$, a distribution of the isoalloxazine-adenine distance in the absence of $Y_{346}$ explaining the multiexponential decay, or (ii) from the $\mathrm{W}_{286}$ residue, possibly accounting for one of the decays. This work supports the idea that H-bond-assisted $\pi-\pi$ stacking controls TrmFO's active site dynamics, required for competent orientation of the reactive centers during catalysis. 


\section{INTRODUCTION}

Flavins (FMN and FAD), which are derivatives of vitamin B2, are considered as the most versatile coenzymes in nature. They are used by flavoproteins as proton, electron, hydride, oxo or methylene transfer agents to catalyze a vast variety of biochemical reactions, mainly dependent on redox chemistry. ${ }^{1,2}$ One of the distinctive functional features of flavins is the diene moiety of their isoalloxazine ring, which allows them to cycle between three main redox states (oxidized, semireduced or fully reduced), each of them potentiality existing under various protonation states. ${ }^{3}$ Far beyond the reactivity of free flavins, it is actually the intimate and often synergistic interactions between the isoalloxazine and its apoprotein partner (ionic, hydrophobic or $\pi-\pi$ stacking) that precisely regulate the physical and chemical properties of these coenzymes. ${ }^{4}$ It is thus important to characterize them, not only for fundamental mechanistic reasons, but also to address the challenges posed by the development of coenzyme-based artificial enzymes. ${ }^{5}$

In this regard, the flavoenzyme TrmFO, a FAD and folate-dependent bacterial tRNA methyltransferase, ${ }^{6-9}$ has recently been a model of choice for deciphering new, exquisite intermolecular interactions between flavin and apoprotein that allow TrmFO to achieve its unique chemical reactivity. ${ }^{10-14}$ While nearly all conventional DNA or RNA methyltransferases catalyze a direct $\mathrm{CH}_{3}$-transfer using S-adenosyl methionine cofactor, ${ }^{15}$ TrmFO exhibits a complex multi-step mechanism wherein reduced $\mathrm{FAD}\left(\mathrm{FADH}^{-}\right)$first mediates a $\mathrm{CH}_{2}$-transfer from the 5,10methylenetetrahydrofolate to tRNA via an unprecedented flavin iminium $\left(F A D=\mathrm{CH}_{2}\right)$ intermediate, and then reduces $\mathrm{CH}_{2}$ to $\mathrm{CH}_{3}$ by transferring a hydride. ${ }^{12,16}$ Since then, the unrelated flavoenzyme ThyX has been shown also to rely on the same intermediate to synthesize the DNA nucleotide dTMP in some bacteria and archae, ${ }^{16-18}$ suggesting that the occurrence of this iminium species could be more widely spread in flavoenzyme reactivity than anticipated. Remarkably, in the absence of tRNA, TrmFO is able to store the otherwise reactive iminium intermediate in the form of a stable proteinFAD adduct via the formation of a covalent $C-S$ bond with a conserved cysteine residue $\left(C_{53}\right.$ in Bacillus subtilis TrmFO, noted BsTrmFO). ${ }^{12}$ According to the crystal structure of Thermus thermophilus TrmFO ( $T t \operatorname{TrmFO}){ }^{7}$ which shares $51 \%$ sequence identity with BsTrmFO, this cysteine ( $C_{51}$ in $T t \operatorname{TrmFO}$ ) lies on a flexible loop at the immediate vicinity of the FAD N5 nitrogen.

In the eager search for molecular phenomena that control the C-S bond formation/cleavage cycle, some of us uncovered the pivotal role of a $\pi$ - $\pi$ stacking interaction assisted by hydrogen bond in promoting proper FAD binding and structure of TrmFO's active site. ${ }^{14}$ This interaction involves three 
key players: a conserved tyrosine $\left(\mathrm{Y}_{346}\right.$ in $\left.B s T r m F O\right)$, the isoalloxazine moiety and the backbone of $\mathrm{C}_{53}$ (Figure S1). ${ }^{7,14}$

Most interestingly, the fluorescence of TrmFO, arising from the oxidized $F A D\left(F A D_{o x}\right)$, is strongly quenched in the wild-type (WT) and C53A proteins while it is much larger when $\mathrm{Y}_{346}\left(\mathrm{Y}_{343}\right.$ in TtTrmFO) is replaced by an alanine or phenylalanine. ${ }^{14,19}$ This quenching effect has been attributed to an efficient electron transfer (ET) from the stacked tyrosine to the flavin. ${ }^{19}$ Similar ET phenomena from aromatic amino acids (Tyr and Trp) to the excited isoalloxazine, resulting in ultrashort excited-state lifetimes, have been previously reported in numerous other flavoproteins. ${ }^{20-30}$ Such ET is very sensitive to the distance of the reactive centers and can reciprocally be considered as reporter of their relative position, as for instance formerly used to explore the structural flexibility of ThyX. ${ }^{31}$ Ultrafast spectroscopy is a particularly suited tool for probing such reactions, which Nag et al. recently applied to investigate the quenching dynamics of two variants of $T t \operatorname{TrmFO}, \mathrm{C} 51 \mathrm{~A}$ and C51A/Y343F. ${ }^{19}$ They showed that upon excitation of FAD $_{\text {ox }}$ at $390 \mathrm{~nm}$, a very fast ET occurs from $\mathrm{Y}_{343}$ to the excited $F A D_{\text {ox }}$ in $\sim 1 \mathrm{ps}$, yielding the flavin radical anion $\left(F A D^{\bullet-}\right)$ and the, formerly uncharacterized, protonated tyrosyl radical cation $\left(\mathrm{Y}_{346} \mathrm{OH}^{\bullet+}\right)$. This radical pair was then seen to recombine in $\sim 3 \mathrm{ps}$, without apparent deprotonation of the tyrosyl cation. This constitutes a remarkable discovery in the field of photochemistry since $\mathrm{YOH}^{\bullet+}$ is usually considered an elusive species because of its extreme acidity (pKa $\sim-2^{32}$ ), favoring its ultrafast deprotonation. ${ }^{32}$ Upon replacement of $\mathrm{Y}_{343}$ by a redox-inert phenylalanine, this ultrafast photoinduced reaction was inhibited. The same effect has been reported for other flavoproteins, as in flavodoxin. ${ }^{22,33}$ In the case of TtTrmFO, a slower and multiphasic decay of the excited state remained, which Nag et al. ${ }^{19}$ attributed to an alternative ET from the $\mathrm{W}_{214}$ tryptophan to the excited flavin. Such type of ET indeed occurs in many other flavoproteins, ${ }^{21,26,34-36}$ but the electron density of $W_{214}$ is not visible in the TtTrmFO structures, ${ }^{7}$ raising uncertainties about its relative position with respect to FAD. Moreover, the corresponding tryptophan is absent from the BsTrmFO sequence, ${ }^{7}$ suggesting that this ET mechanism could be limited to the Thermus thermophilus enzyme.

In the present work, we have measured for the first time the photoinduced flavin dynamics of BsTrmFO in both the WT and the C53A mutant, by ultrafast transient absorption spectroscopy. Contrary to TtTrmFO, it is indeed possible to prepare WT-BsTrmFO samples containing a reduced fraction of methylene-FAD-protein adduct, thereby allowing the selective excitation of the $F A D_{o x}$ by choosing a wavelength where the adduct absorbs much less than $F A D_{o x}$, here $475 \mathrm{~nm}$. The comparison of WT and C53A is meant to evaluate the possible role of the $C_{53}$ residue on the FAD- $Y_{346}$ interaction and on the dynamics of TrmFO's active site, although the C53A mutation does not necessarily cancel the hydrogen bond between $Y_{346}$ and the backbone of $C_{53}$. In addition, several $Y_{346}$ single mutants of BsTrmFO (Y346A, Y346M and Y346F) were studied to investigate the 
aforementioned secondary quenching channels, in the absence of $Y_{346}$ and of any equivalent to the $\mathrm{W}_{214}$ of $T t$ TrmFO.

\section{MATERIALS AND METHODS}

\subsection{Samples}

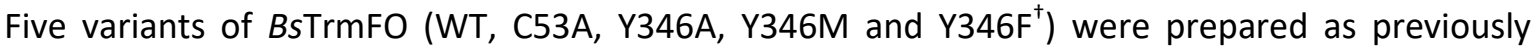
described. ${ }^{14,37}$ As previously observed, ${ }^{13}$ overnight exposure of freshly purified WT BsTrmFO to air significantly reduced the amount of reduced $\mathrm{FAD}-\mathrm{CH}_{2}-\mathrm{C}_{53}$ adduct, which presents a maximum absorption around $360 \mathrm{~nm},{ }^{12,16}$ and completely removed the $\mathrm{FAD}-\mathrm{CH}_{2}-\mathrm{C}_{53}{ }^{\bullet}$ radical, an inactive oneelectron oxidized product of the latter adduct. The Y346 mutants were isolated from E. coli as apoproteins. To reconstitute the corresponding holoproteins, each freshly purified apoprotein was incubated with two equivalent of $\mathrm{FAD}_{\mathrm{ox}}$ and the unbound flavin was then removed on a PD10 desalting column as detailed previously. ${ }^{14,16}$

The steady-state absorption spectra of the samples used for transient absorption spectroscopy are provided in ESI, Section S2 (Figure S2). All BsTrmFO mutants essentially exhibit the characteristic bands of $F A D_{o x}{ }^{36,38-40}$ here situated around 375 and $445 \mathrm{~nm}$. The WT spectrum additionally contains a contribution of the methylene-FAD adduct, around $360 \mathrm{~nm}$. We estimated that the fraction of methylene-FAD adduct in our WT sample is of the order of $40 \%$ and that, under excitation at 475 $\mathrm{nm}$, the fraction of excited flavin in adduct form is limited to $\sim 5 \%$, which can reasonably be neglected (see details in ESI, Section S2). In the case of 405-nm excitation, this fraction is however too large to be neglected (15\%); we therefore present only results on WT with excitation at $475 \mathrm{~nm}$.

\subsection{Transient absorption spectroscopy}

Broadband transient absorption spectra were recorded by the pump-probe technique with whitelight continuum probe, as previously described. ${ }^{40}$ The pump beam was tuned at $475 \mathrm{~nm}$ with a noncollinear optical parametric amplifier (NOPA, Clark MXR) for most experiments. Complementary recordings were made under excitation at $405 \mathrm{~nm}$, obtained by frequency doubling of the laser source beam in a BBO crystal. ${ }^{39}$ It was checked by comparison with a reference sample of $\left[\mathrm{Ru}(\mathrm{bpy})_{3}\right]^{2+}$ complex ${ }^{41,42}$ that the fraction of excited molecules in the probed volume was about $4 \%$, ensuring excitation in the linear regime. Experiments under 475-nm excitation were performed with polarized probe ${ }^{36}$ thereby allowing access to transient anisotropy data in addition to the standard isotropic

\footnotetext{
'The notation 'WT' will often be used as an abbreviation for 'wild-type BsTrmFO'. Similarly, 'C53A', 'Y346A', 'Y346M' and 'Y346F' alone will be used to refer to the different mutants of BsTrmFO.
} 
transient absorption spectra (see below). The experiments under 405-nm excitation were performed at the magic angle configuration of pump and probe polarizations, which only provides isotropic spectra. $^{39}$

The samples were contained in 1-mm optical path quartz cells (width: $2 \mathrm{~mm}$, containing $\sim 60 \mu \mathrm{L}$ ) and kept at $10^{\circ} \mathrm{C}$ with a thermostated holder. The sample cell was continuously moved back and forth in horizontal and vertical directions to avoid exciting the same region consecutively. Steady-state absorption spectra of the samples were regularly recorded during the experiments to check that no sample degradation occurred.

The raw differential absorption spectra were first corrected from the chirp of the probe beam, which was independently measured by recording cross-phase modulation ${ }^{43}$ (XPM) in the pure solvent. When available, the polarized transient spectra $\left(\Delta \mathrm{A}_{\|}\right.$and $\left.\Delta \mathrm{A}_{\perp}\right)$ were replaced by the isotropic transient absorption spectra $\left(\Delta \mathrm{A}_{\text {iso }}\right)$ and the transient anisotropy spectra $(r)$, with the standard definitions of Equations 1 and 2. Note that the anisotropy based on transient absorption spectra is a complex quantity that may in particular diverge when the denominator (isotropic signal) vanishes. The individual contributions coming the different transitions of the different involved species may formally be accounted for by a well-known addition rule. ${ }^{44}$ This approach was however not employed in the present work and anisotropy was simply used at a qualitative level.

$$
\left\{\begin{array}{l}
\Delta \mathrm{A}_{\text {iso }}=\frac{1}{3}\left(\Delta \mathrm{A}_{\|}+2 \Delta \mathrm{A}_{\perp}\right) \\
\mathrm{r}=\frac{\Delta \mathrm{A}_{\|}-\Delta \mathrm{A}_{\perp}}{\Delta \mathrm{A}_{\|}+2 \Delta \mathrm{A}_{\perp}}
\end{array}\right.
$$

Non-correctable scattering of the pump beam was masked in the transient spectra. The 405-nm excitation was in fact essentially used to displace the masked region and uncover the spectrum around $475 \mathrm{~nm}$ in the experiment with $475-\mathrm{nm}$ excitation. The drawback is that an additional excess energy $\left(3639 \mathrm{~cm}^{-1}\right)$ was given to the flavin molecules upon excitation at $405 \mathrm{~nm}$.

\subsection{Data analysis}

Multiexponential global analysis with singular value decomposition ${ }^{45}$ was performed simultaneously on the parallel and perpendicular spectra, as described previously. ${ }^{36}$ Effective fits of the isotropic and anisotropy data were deduced from these fits with Equations 1 and 2. In the case of 405-nm excitation, simple analysis of the isotropic data was done.

The global fits are characterized by a series of time constants and associated pre-exponential factor spectra, called decay-associated difference spectra (DADS). The fits are however more conveniently summarized by the so-called evolution-associated difference spectra (EADS), which correspond to the states a virtual cascading model with $100 \%$ quantum yield between one state and the following 
one. ${ }^{46}$ When available, the polarized EADS were converted into isotropic EADS and evolutionassociated anisotropy spectra (EAAS) with Equations 1 and 2.

It may be noted that in the above global analysis, all phenomena are decomposed into a sum of kinetic traces (exponentials) associated to time-independent spectra (DADS). This treatment hence does not explicit treat the case of continuous shifting or deforming bands. To analyze this type of behavior, a specific analysis as to be devised, such as tracking the position and intensity of the maximum of a given band as a function of time (see 4.1.1).

\section{RESULTS}

\subsection{Transient absorption spectroscopy of the wild-type BsTrmFO}

A selection of isotropic transient absorption spectra of WT-BsTrmFO, recorded between 0.3 and $3.2 \mathrm{~ns}$ after excitation at $475 \mathrm{~nm}$, are shown in Figure 1 (A-C).

At $0.3 \mathrm{ps}$ (Figure $1 \mathrm{~A}$ ), the spectrum exhibits two negative bands peaking at 446 and $550 \mathrm{~nm}$; the first one is dominated by ground-state bleaching (GSB) and the second one by stimulated emission (SE). Three positive bands dominated by transient absorption (TA) are also seen: at $365 \mathrm{~nm}$ with a minor shoulder around $400 \mathrm{~nm}$ (named $\mathrm{TA}_{1}$ ), at $511 \mathrm{~nm}\left(\mathrm{TA}_{2}\right)$ and from 600 to $750 \mathrm{~nm}\left(\mathrm{TA}_{3}\right)$. These are typical features of excited $F A D_{o x}\left(F A D_{o x}{ }^{*}\right)$ already reported for other oxidized flavoproteins ${ }^{26,36,40,47,48}$ and free $F A D$ in solution. ${ }^{39,49}$

From 0.3 to $1.8 \mathrm{ps}$ (Figure $1 \mathrm{~A}$ ) the intensity of all bands decrease with the notable exception of the $\mathrm{TA}_{2}$ band that increases until 0.9 ps before starting to decrease (Figure $1 \mathrm{~A}$ ). Simultaneously the $\mathrm{TA}_{1}$ band decreases, more rapidly on its blue side $(365 \mathrm{~nm})$ than on its red side $(400 \mathrm{~nm})$, thereby acquiring a broader shape. The SE band concomitantly shifts to the red (to $559 \mathrm{~nm}$ ) and its net negative part reduces to a small region, suggesting that it is overlapped with some strong transient absorption band.

From 1.8 ps to 22 ps (Figure 1B), the TA and GSB bands go on decaying with some changes of shape: the $\mathrm{TA}_{1}$ band becomes narrower again and relatively more intense than the GSB and $T A_{2}$ bands. Concomitantly, the SE band broadens rather than decaying and its net negative part widens again.

After $22 \mathrm{ps}$, a spectrum resembling that of $\mathrm{FAD}_{\mathrm{ox}}{ }^{*}$ slowly decays on the sub-ns timescale (Figure $1 \mathrm{C}$ ). The shape of the $\mathrm{TA}_{1}$ band further changes during this step, with the progressive reduction of the shoulder at $400 \mathrm{~nm}$. A small residual spectrum is observed at $3.2 \mathrm{~ns}$.

The transient absorption spectra were globally fitted by a sum of 5 exponentials followed by a plateau. The obtained time constants are: $0.38,1.15,4.1,43$ and 700 ps (Table 1). The corresponding isotropic DADS are given in ESI, Section S4.1 and the EADS in Figure 2A. Figure S5A in ESI, Section S5.1 
shows the same spectra normalized at the maximum of their bleaching band, in order to better distinguish the changes of shape between them.

The initial excited-state decay takes place in $0.38 \mathrm{ps}$ and $1.15 \mathrm{ps}$. During these steps, the EADS (Figure $2 \mathrm{~A}$; Figure S5A) clearly show the evolution of the $\mathrm{TA}_{1}$ band (growth of the $400-\mathrm{nm}$ shoulder), the shift of the SE band and the increase of the $\mathrm{TA}_{2}$ band. The $\mathrm{TA}_{2}$ band then decays in $4.1 \mathrm{ps}$, together with the $\mathrm{TA}_{1}$ band whose shape changes again (reduction of the shoulder). During the remaining kinetic steps (43 ps, $710 \mathrm{ps)}$ ), all bands decay but the relative intensity of the $\mathrm{TA}_{1}$ and SE bands diminishes during the last phase. The final spectrum (plateau) exhibits a net negative SE band, indicating the persistence of a long-lived excited flavin population.

\subsection{Transient absorption spectroscopy of the C53A mutant}

Figure 1 (D-E) shows a selection of isotropic transient absorption spectra of the C53A mutant, recorded between 0.3 ps and 100 ps, after excitation at $475 \mathrm{~nm}$. Globally, the behavior of C53A resembles that of WT but is in fact simpler, with fewer kinetic phases.

Like in the case of WT, the spectrum at 0.3 ps has the characteristic signature of $F A D_{o x}{ }^{*}$, with a TA bands at 365, 506 and above $610 \mathrm{~nm}$, a GSB band at $444 \mathrm{~nm}$ and a SE band at $550 \mathrm{~nm}$. From $0.3 \mathrm{ps}$ to 1.7 ps (Figure 1D) the spectral evolution is similar to that of WT: all bands decay except for $\mathrm{TA}_{2}$ that on the contrary increases until $1.1 \mathrm{ps}$ before starting to decrease. The $\mathrm{TA}_{1}$ band becomes rounder and broader while the SE band shifts to $555 \mathrm{~nm}$ and only appears as a dip on a positive background, indicating that SE becomes dominated by TA in this region. A clear difference with WT appears from 1.7 ps to 22 ps (Figure 1E): the decay of the TA and GSB bands is here much more pronounced. The intensity of the GSB and $T A_{2}$ bands first increase relatively to that of the $\mathrm{TA}_{1}$ and $T \mathrm{~A}_{3}$ bands. After 10 ps, no more changes of spectral shape are observed. A very small residual spectrum remains at 100 ps (Figure 1E-inset).

The transient absorption spectra of C53A could be fitted with a reduced sum of four exponentials, with time constants $0.30,1.0,3.0$ and 9.3 ps (Table 1 ), followed by a plateau. The corresponding DADS are provided in ESI, Section S4.1. The EADS are presented in Figure 2B (normalized EADS are shown in Figure S5B of ESI, Section S5.1).

As well seen on the EADS, most of the initial excited-state decay occurs in $0.3 \mathrm{ps}$; it then goes on in $1.0 \mathrm{ps}$ while the $\mathrm{TA}_{2}$ band increases. The final decay of all bands in fact proceeds with two time constants: 3.0 ps and 9.3 ps. The very small plateau of the fit (inset in Figure $2 \mathrm{~B}$ ) accounts for the remaining signal observed at $100 \mathrm{ps.} \mathrm{One} \mathrm{may} \mathrm{note} \mathrm{a} \mathrm{keen} \mathrm{resemblance} \mathrm{of} \mathrm{EADS5} \mathrm{and} \mathrm{EADS1,} \mathrm{which}$ suggests that the population responsible for the plateau is composed of excited flavins.

In order to reveal the spectral region masked by scattering of the pump beam (around $475 \mathrm{~nm}$ ), additional experiments were performed with excitation at $405 \mathrm{~nm}$ (magic angle only; raw spectra not 
shown). The isotropic spectra were satisfactorily fitted by the same model as above; the obtained time constants (see Table S1 in ESI, Section S3), as well as DADS (ESI, Section S4.2) and EADS (ESI, Section S5.2) are very similar to the ones obtained with excitation at $475 \mathrm{~nm}$.

\subsection{Transient absorption spectroscopy of the $Y_{346}$ mutants}

Since the transient absorption behavior of the three studied $\mathrm{Y}_{346}$ mutants (Y346A, Y346M and Y346F) are quite similar, only that of Y346A will here be described in details. Selected isotropic spectra of Y346A, recorded between 0.3 ps and $3.2 \mathrm{~ns}$ after excitation at $475 \mathrm{~nm}$, are shown in Figure 3.

At 0.3 ps one observes the same characteristic features of $\mathrm{FAD}_{\mathrm{ox}}{ }^{*}$ as previously detailed. The subsequent spectral evolution is however completely different, with a much slower amplitude decay accompanied by considerably smaller changes of shape. From 0.3 ps to 100 ps, one observes only a moderate decrease of most of the bands (the $\mathrm{TA}_{2}$ band however remains approximately constant). The shape of the $\mathrm{TA}_{1}$ band does not change but a shift of the SE band to $565 \mathrm{~nm}$ is observed. Between 100 ps and 3.2 ns, most bands decay more strongly (except $\mathrm{TA}_{3}$ ), without shift of the SE band. The shape of the $\mathrm{TA}_{1}$ band concomitantly changes, with a relative intensity increase of the shoulder at $390 \mathrm{~nm}$.

The transient absorption data were fitted by a sum of three exponentials and a plateau. The time constants $(4.0,100$, and 1600 ps) are recalled in Table 1, together with the close ones of Y346M and Y346F. The corresponding DADS may be found in ESI, Section S4.1 and the EADS in Figure 2C. The first three EADS are very similar in shape (see normalized EADS in Figure S5C), the main difference between them being the SE band that progressively shifts to the red; the concomitant relative increase of the $\mathrm{TA}_{2}$ band is in fact likely the mere consequence of that shift (reduction of negative SE contribution). The excited-state decay is seen to be distributed over the three time constants, the last one being predominant. The last EADS (plateau) is quite different from the others: it features a larger shoulder at $390 \mathrm{~nm}$ and many changes in the relative intensities of the various bands. The presence of a marked dip in the SE region (around $567 \mathrm{~nm}$ ) suggests that a sub-population of excited flavin remains in the ns timescale.

As seen in Figure 2(D-E), the EADS of Y346M and Y346F highly resemble those of Y346A. It may however be observed that the spectra of $\mathrm{Y} 346 \mathrm{M}$ show larger variations, in particular in the $\mathrm{TA}_{1}$ band below $400 \mathrm{~nm}$. This effect is likely related to corresponding minor differences observed in the steadystate absorption spectra (Figure S2), assigned to a somewhat less rigid environment of $F A D_{o x}$ in Y346M (ESI, Section S2). It is thus expected that the different GSB contribution slightly alters the transient absorption spectra. It is also possible that the same cause also mildly modifies the pure TA 
and SE contributions, yielding the observed result. The overall dynamics of all $Y_{346}$ mutants are however very similar and will be interpreted within the same framework (Section 4.3).

Upon excitation at $405 \mathrm{~nm}$, the general behavior described above is also observed, with the notable difference that an additional very short time constant (0.4-0.6 ps depending on the protein) is necessary to fit the transient absorption spectra of all $\mathrm{Y}_{346}$ mutants. The time constants are provided in Table S1 of ESI, Section S3, and the corresponding DADS and EADS in ESI, Section S4.2 and ESI, Section S5.2, respectively.

\subsection{Transient anisotropy}

From all polarized experiments with excitation at $475 \mathrm{~nm}$, transient absorption anisotropy spectra could be deduced with Equation 2 (not shown). The evolution-associated anisotropy spectra (EAAS) deduced from the global analysis of the data are presented in ESI, Section S6 (Figure S8).

In brief, the isotropic spectral evolutions described in the previous sections are also reflected at the anisotropy level. For WT and C53A, very large anisotropy changes accompany the fast excited-state decay, in particular in the SE region where the isotropic signal changes sign and crossing points $\left(\Delta A_{\text {iso }}=0\right.$; hence diverging anisotropy) continuously change. It should be noted in the simpler case of C53A that EAAS3, associated to the first photoproduct following the decay of the excited state, exhibits a marked dip around $564 \mathrm{~nm}$, curiously evoking the shape of a SE band as seen in isotropic spectroscopy. A similar feature has previously been described in the context of the flavin photoreduction of a class II photolyase ${ }^{50}$ and assigned to small remnants of excited flavin population. We thus highly suspect such a contamination in the present case, and will return to this issue in the Discussion section (Section 4.1.3). We may finally observe that the final EAAS bears an interesting resemblance with the initial EAAS1 (especially marked for C53A), which supports the abovementioned (Section 3.2) hypothesis that the plateau would be due to a small population of excited flavins.

As far as the $\mathrm{Y}_{346}$ mutants are concerned, one observes very little evolution of the anisotropy during the first two kinetic steps. Only minor changes related to the shift of the SE band (hence shift of the crossing points and associated anisotropy divergences) are observed. This pretty good invariance will be commented in Section 4.3.1. The main anisotropy changes are seen during the last kinetic step, in the ns timescale. Again, EAAS4 exhibits a more or less pronounced dip in the SE region, likely related to the persistence of a long-lived excited flavin population. This issue will be discussed further in Section 4.3.2. 


\section{DISCUSSION}

\subsection{Ultrafast dynamics of C53A}

Since the transient absorption behavior of the C53A mutant of BsTrmFO turned out to be simpler than the one of the WT protein, the former will be discussed first. The additional dynamic features of WT will be commented in Section 4.2.

\subsubsection{Charge separation}

The transient absorption behavior of C53A (Section 3.2) clearly shows that the flavin excited state very rapidly decays to form a new product. This process is characterized by the disappearance of the SE band and the growth of a TA band around $500 \mathrm{~nm}$ (more completely seen with excitation at 405 $\mathrm{nm}$; ESI, Section S5.2). Since this spectral dynamics is completely inhibited in the case of all studied $Y_{346}$ mutant (Section 0), the predominant role of the electron donating character of $Y_{346}$ in this reaction is established.

Following the same analysis previously developed by Nag et al. for the C51A mutant of $T t \operatorname{TrmFO},{ }^{19}$ it appears extremely likely that the excited flavin gets reduced to $F A D^{\circ-}$ by $Y_{346}$. The high rate of the reaction is readily explained within the Marcus electron transfer (ET) theory ${ }^{51,52}$ by the very short distance between $\mathrm{Y}_{346}$ and FAD (2.7 $\AA$; Figure S1) and their stacked configuration. It may furthermore be deduced that the produced tyrosyl radical is most probably still protonated (and here noted $\mathrm{Y}_{346} \mathrm{OH}^{\bullet+}$ ) because the 500-nm photoproduct band does not match the well-known spectroscopic signature of deprotonated tyrosyl radical $\left(\mathrm{YO}^{\circ}\right)$, which exhibits a weak absorption band around $405 \mathrm{~nm}^{53,54}$ One may indeed check with the example of an animal-like cryptochrome that a typical transient absorption spectrum of the $\mathrm{FAD}^{\bullet-} / \mathrm{YO}^{\bullet}$ radical pair is pretty flat in the $500-\mathrm{nm}$ region, ${ }^{55}$ and does not resemble the specific shape of EADS3. As noted by Nag et al., ${ }^{19}$ the observation of the $\mathrm{YOH}^{\bullet+}$ radical is exceptional because this species is known to be extremely acidic ( $\mathrm{pKa} \sim-2^{32}$ ) and therefore expected to deprotonate rapidly. One may think that its observation in TrmFO is permitted by the very high rate of its formation. It may additionally be hypothesized that the particular $\mathrm{H}$-bond between $\mathrm{Y}_{346}$ and the amide group of $\mathrm{C}_{53}$ stabilizes the protonated tyrosyl radical, increasing its pKa and thereby slowing down its deprotonation.

It is interesting to emphasize that the photoreduction of the flavin is biexponential ( 0.30 and $1.0 \mathrm{ps})$ whereas a single exponential of 1.1 ps was reported by Nag et al. for the C51A mutant of TtTrmFO. ${ }^{19}$ It may further be noted that DADS1 and DADS2 (ESI, Section S4.1, Figure S3B) have very different shapes which allows us to rule out the possibility that the two fast components would correspond to two populations of the protein (e.g. characterized by different FAD- $Y_{346}$ distances) undergoing the same ET process at different rates. We rather believe that they are two phases of the same process. 
Inspection of the normalized EADS (Figure S5B) reveals that the first phase consists in a partial decay of the SE band, accompanied by a small red shift $(\sim 5 \mathrm{~nm})$ of the latter. The $500-\mathrm{nm}$ band concomitantly starts to rise and the $400-\mathrm{nm}$ shoulder to grow. The second phase sees the final decay of the SE band and growth of the 500-nm band. To explain this behavior, we propose that the ET from $Y_{346}$ to $F A D_{o x}{ }^{*}$ is in fact coupled to a fast relaxation of $F A D_{0 x}{ }^{*}$, due the response of the flavin environment (protein residues or nearby water molecules) to the change of charge distribution induced by the excitation. ${ }^{56-59}$

Within this interpretation, we intended to separate the two phenomena by tracking the spectral position and the intensity of the maximum of the SE as a function of time. We found that both curves could be fitted by a single exponential decay (Figure 4): the red shift dynamics is characterized by a time constant of $1.3 \mathrm{ps}$, while the pure excited-state decay, hence the flavin reduction, takes place in $0.43 \mathrm{ps}$ (this time constant is noted in the simplified reaction Scheme 1). This fast coupled dynamics was interestingly not reported for $T t \operatorname{TrmFO},{ }^{19}$ which may tentatively be related to the fact Thermus thermophilus is a thermophile organism and that TtTrmFO is likely more rigid than BsTrmFO. ${ }^{60}$ This extra rigidity might in turn be thought to reduce the response of the flavin environment to the optical excitation. It may further be noted that the rate of flavin reduction of BsTrmFO deduced from the above analysis $\left(2.7 \mathrm{ps}^{-1}\right)$ is significantly faster than the one of $T t \operatorname{TrmFO}\left(0.91 \mathrm{ps}^{-1}\right)$. This difference (factor of 2.6) could be due to the slightly smaller FAD-Y ${ }_{346}$ distance in BsTrmFO (2.7 $\AA$ ) than in $T t \operatorname{TrmFO}\left(3.3 \AA \AA\right.$ according to PDB entry $3 \mathrm{G} 5 \mathrm{~S}^{7}$ ). For illustrative purpose only, let us mention that Page et al.'s empirical formula for Marcus $\mathrm{ET}^{52}$ (see details in Section 4.3.1) predicts a decrease of the rate constant by a factor of $\sim 2.3$ if the distance is increased by $0.6 \AA$ (all other factors being held constant), in qualitative agreement with the experimental values. This estimation is however to be taken with precaution because: (i) of the uncertainty on the FAD- $Y_{346}$ distance, only obtained from a homology model in BsTrmFO and (ii) of the fact that for extremely fast ET, the above formula (exponential decay of the rate with distance) might not be valid, as recently discussed for other flavoproteins. ${ }^{28,30,61}$

\subsubsection{Charge recombination}

Following the initial charge separation described above, the analysis of Section 3.2 shows that all photoproduct bands rapidly decay, with time constants of 3.0 and $9.3 \mathrm{ps}$. The residual spectral remaining after this decay (DADS5) is so small that is can for now be neglected. It can therefore be deduced that the $\mathrm{FAD}^{\bullet-} / \mathrm{Y}_{346} \mathrm{OH}^{\bullet+}$ radical pair undergoes charge recombination during these phases, yielding the restoration of the starting oxidized flavin configuration. The biexponential nature of this process is specific to BsTrmFO as a single component of $3.0 \mathrm{ps}$ was reported for TtTrmFO. ${ }^{19}$ 
Careful inspection reveals that DADS3 and DADS4 have quite similar shapes, although some differences may be distinguished (slightly different position of the bleaching band, different relative intensity of the 500-nm band). One could first conceive that these two kinetic components correspond to two distinct populations, undergoing charge recombination at slightly different rates, possibly because of some minor structural differences, also justifying the difference of shape of DADS3 and DADS4. Within this hypothesis, the population decaying in 3.0 ps would be dominant, representing about $84 \%$ of the total decay (fraction measured in the $380-\mathrm{nm}$ band; this time constant is noted in the simplified reaction Scheme 1). It might alternatively be considered that charge recombination restores the flavin in a hot ground state, as recently reported for semi-reduced flavodoxin, ${ }^{62}$ and that the altered absorption spectrum of hot $F A D_{o x}$ contributes to DADS4. However, since DADS4 retains a high similarity with DADS3, it is unlikely that the fourth kinetic step can be assigned to ground-state cooling alone. Charge recombination must still be the major contributor to it. We rather favor a third hypothesis, along which the spectroscopic signature of the $\mathrm{FAD}^{\circ-} / \mathrm{Y}_{346} \mathrm{OH}^{\bullet+}$ pair would continue to evolve during the recombination process, possibly due to the response of the protein environment to the new charge distribution or to some cooling process of the radical pair, initially produced in a hot vibrational state as earlier proposed for a plant cryptochrome ${ }^{26}$ and a (6-4) photolyase. $^{36}$

It may finally be mentioned that deprotonation of the $\mathrm{Y}_{346} \mathrm{OH}^{\bullet+}$ radical does not take place during the 3.0-ps and 9.3-ps steps as the characteristic spectrum of $\mathrm{FAD}^{\circ-} / \mathrm{YO}^{\bullet},{ }^{55}$ with weak and flat profile above $500 \mathrm{~nm}$, is not observed here. As mentioned above, it may be speculated that $\mathrm{Y}_{346} \mathrm{OH}^{\bullet+}$ is in fact stabilized by the unusual $\mathrm{H}$-bond between $\mathrm{Y}_{346}$ and the amide group of $\mathrm{C}_{53}$, which would slow down the expected fast deprotonation of this radical.

\subsubsection{Corrections to EADS3 and EADS4}

We will next intend to extract from EADS3 and EADS4 the pure spectrum of the $F A D_{\text {ox }}$ radical pair. This operation will be best performed with the EADS obtained with excitation at $405 \mathrm{~nm}$ (see ESI, Section S5.2), because the spectra are better defined in the critical region around $500 \mathrm{~nm}$. In addition, the missing data around $405 \mathrm{~nm}$ may be rather well be filled by a straight line without much loss of information (e.g. compare Figures S5B and S7A). Let us however first mention two difficulties that need to the solved before proceeding to any calculation.

In the first place, the weak plateau observed at long pump-probe delays contributes by construction to all EADS. In order to focus on the species undergoing fast dynamics, EADS5 was subtracted from all EADS, yielding so-called EADS' (numbered from 1 to 4 ) as shown in Equation 3.

$$
\left\{\begin{array}{l}
\mathrm{EADSi}^{\prime}=\mathrm{EADSi}-\mathrm{EADS} 5 \\
\mathrm{EADSi}^{\prime \prime}=\mathrm{EADSi}^{\prime}-\alpha_{\mathrm{i}} \mathrm{EADS}^{\prime}
\end{array}\right.
$$


The second issue is the presence of a dip, evoking the shape of a SE band, in the anisotropy spectra EAAS3 and EAAS4 (with 475-nm excitation; Figure S8B). To check whether this comes from remnants of excited flavin population, a variable fraction of EADS1' was subtracted from EADS3' and EADS4', as shown in Equation 4. Factor $\alpha$ should be interpreted the fraction of the initial population remaining in the excited state. This operation was done for both polarizations (with the same factor $\alpha_{i}$ ) and corrected anisotropy spectra (noted EAAS") were calculated from the results with Equation 2. We found that the dip could be satisfactorily suppressed with $\alpha_{3}=0.07$ and $\alpha_{4}=0.02$ (Figure 5). With this choice, EAAS3" and EAAS4" adopt a similar shape, with a smooth variation of the anisotropy between 500 and $700 \mathrm{~nm}$, which likely reflects the transition from a region where both $\mathrm{FAD}^{\circ-}$ and $\mathrm{YOH}^{\bullet+}$ species contribute to a region where only $F A D^{\bullet-}$ contributes, without interference from $\mathrm{FAD}_{\mathrm{ox}}{ }^{*}$. The corresponding EADS", shown in Figure 6A, have also a smother shape between 500 and $700 \mathrm{~nm}$ and one can observe that a shallow depression in the SE region has been compensated. It is however obvious that such a compensation could not have been made with the EADS alone. Only do the EAAS provide the sufficient sensitivity to reveal the minor $\mathrm{FAD}_{\mathrm{ox}}{ }^{*}$ population.

Given that polarized experiments were not available with excitation at $405 \mathrm{~nm}$, we assumed that the same fraction of the initial excited state remained in EADS3 and EADS4 and the latter spectra were corrected with the same choice of $\alpha$ parameters as above. The results, similar to the previous case, are shown in Figure 6B.

A view of the same corrected EADS, arbitrarily normalized around $385 \mathrm{~nm}$ is provided in ESI, Section S7. Figure S9B in particular illustrates the clear difference of shape of EADS3" and EADS4", with relatively more pronounced and blue shifted peaks at 438 and $490 \mathrm{~nm}$ for EADS4".

\subsubsection{Spectrum of the radical pair}

To extract a pure spectrum of the $\mathrm{FAD}^{\bullet-} / \mathrm{Y}_{346} \mathrm{OH}^{\bullet+}$ radical pair, we used the standard decomposition of the relevant difference spectrum $\left(\Delta A_{r p}\right)$ into the sum of Equation 5 , where $c_{r p}$ is the concentration of radical pair, the $\varepsilon_{i}$ are the molar absorption coefficients of the different species and $\mathrm{L}$ is the optical path. The $\varepsilon_{\mathrm{YOH}^{+}}+\varepsilon_{\mathrm{FAD}^{*-}}$ spectrum then follows from bleaching compensation as shown in Equation 6.

$$
\left\{\begin{array}{l}
\Delta \mathrm{A}_{\mathrm{rp}}=\mathrm{c}_{\mathrm{rp}}\left(\varepsilon_{\mathrm{FAD}^{\cdot-}}+\varepsilon_{\mathrm{YOH}^{++}}-\varepsilon_{\mathrm{FAD}_{\mathrm{ox}}}\right) \mathrm{L} \\
\varepsilon_{\mathrm{YOH}^{{ }^{+}}}+\varepsilon_{\mathrm{FAD}^{{ }^{-}}}=\frac{\Delta \mathrm{A}_{\mathrm{rp}}}{\mathrm{c}_{\mathrm{rp}} \mathrm{L}}+\varepsilon_{\mathrm{FAD}_{\mathrm{ox}}}
\end{array}\right.
$$

To evaluate Equation 6 , it is straightforward to get the $\varepsilon_{\mathrm{FAD}_{\mathrm{ox}}}$ spectrum by normalizing the absorption spectrum of the protein (see ESI, Section S2). The choice of $c_{r p}$ is however more critical and depends on the $\Delta \mathrm{A}_{\mathrm{rp}}$ spectrum taken for the calculation.

Using EADS3", it is reasonable to assume that the quantum yield of radical pair formation at that kinetic step is one, because of the extreme rapidity of the charge separation process (0.43 ps). We 
can thus take the initial excited state concentration as an estimate of $c_{r p}$. In turn, $c^{*}$ was estimated to $10.9 \mu \mathrm{M}$ using the transient spectra of the $\left[\mathrm{Ru}(\mathrm{bpy})_{3}\right]^{2+}$ complex recorded under the same conditions, as previously detailed. ${ }^{63}$ The obtained spectrum (blue line in Figure 7; called for short $\mathrm{RP}_{3}$ ) should of course be taken with some care but we note that changing $c_{r p}$ by $\pm 20 \%$ did not alter much the overall shape of the spectrum. Two bands may be seen: the one peaking at $377 \mathrm{~nm}$ is assigned to $\mathrm{FAD}^{\bullet-}$ and the one at $445 \mathrm{~nm}$ to $\mathrm{Y}_{346} \mathrm{OH}^{\bullet+}$. We believe it is not reliable to go further and extract a pure spectrum of $\mathrm{Y}_{346} \mathrm{OH}^{\bullet+}$ because the absorption spectrum of $\mathrm{FAD}^{\bullet-}$ is not known in TrmFO. One has thus to use a spectrum taken from another flavoprotein, as done by Nag et al. for TtTrmFO. ${ }^{19}$ Different choices were tested ${ }^{64-66}$ (one example is provided in ESI, Section S9 for illustrative purpose) but very incomplete compensations were obtained below $420 \mathrm{~nm}$ (yielding unphysical negative values), which suggests that the spectrum of $F A D^{\bullet-}$ for BsTrmFO has specific spectral features, possibly exhibiting a much less prominent sub-peak around $400 \mathrm{~nm}$ than in other proteins. ${ }^{64-66}$ It may just be mentioned that, since the absorption spectrum of $\mathrm{FAD}^{\circ-}$ is generally of relative lower amplitude between $c a .420$ and $490 \mathrm{~nm}$ and in some cases quite flat, ${ }^{65,66}$ the maximum we observe at $445 \mathrm{~nm}$ may be close to that of the pure $\mathrm{Y}_{346} \mathrm{OH}^{\bullet+}$. A much more red-shifted maximum (490 nm) was however reported by Nag et al. for TtTrmFO. ${ }^{19}$ Such a red maximum could also have been obtained in the present case, but at the cost of a much reduced $c_{r p}$, hardly compatible with our estimation of $c^{*}$, and of visible negative features due to incomplete bleaching compensation.

Taking EADS4" as starting difference spectrum is a more difficult task because a large amount of charge recombination has already taken place at that step. We therefore adjusted $c_{r p}$ so as to produce a spectrum of similar shape as $\mathrm{RP}_{3}$. With a value of $2.1 \mu \mathrm{M}, \mathrm{RP}_{4}$ was obtained (red line in Figure 7). Even if this spectrum is somewhat arbitrary, it should be mentioned that no choice of $c_{r p}$ led to exactly identical $\mathrm{RP}_{3}$ and $\mathrm{RP}_{4}$. The band of $\mathrm{RP}_{4}$ around $450 \mathrm{~nm}$ systematically tends to have a different shape; with our choice of $c_{r p}$, it appears both slightly red-shifted and slightly narrower. We propose that this spectral change is related to a relaxation the $\mathrm{Y}_{346} \mathrm{OH}^{\bullet+}$ radical during the recombination process, either due to the response of its immediate environment or to vibrational cooling (as evoked in Section 4.1.2).

The $445-\mathrm{nm}$ band in the RP spectra of Figure 7 bears a remarkable similarity with the broad absorption spectrum of the radical cation of 2,6-di-tert-butyl-4-methylphenol $\left(\mathrm{ArOH}^{\bullet+}\right),{ }^{67}$ which is centered at $450 \mathrm{~nm}$ in a glassy matrix of $\mathrm{Bu}^{5} \mathrm{Cl}$ at $77 \mathrm{~K}$. It is worth noting that the corresponding spectrum of $\mathrm{ArO}^{\circ}$ at $107 \mathrm{~K}$ has a much narrower peak at $401 \mathrm{~nm} .{ }^{67}$ The same trend has been observed for phenol in a frozen matrix argon, with a band of the radical cation $\left(\mathrm{PhOH}^{\bullet+}\right)$ at $423 \mathrm{~nm}$ while the deprotonated radical $\left(\mathrm{PhO}^{\circ}\right)$ has a narrow peak at $396 \mathrm{~nm} .{ }^{68}$ Similarly, the radical cation and neutral radical of 4-methoxyphenol were reported at 440 and $410 \mathrm{~nm}$, respectively. ${ }^{69}$ These comparisons globally support our assignment of the $445-\mathrm{nm}$ band to $\mathrm{Y}_{346} \mathrm{OH}^{\bullet+}$. 


\subsubsection{Slowly decaying species}

To conclude the examination of the C53A results, let us recall that a very weak plateau (EADS5) remains after decay of all the fast components. In the experiment with excitation at $475 \mathrm{~nm}$, EADS5 has the typical spectral signature of excited $\mathrm{FAD}_{\text {ox }}$ (insert of Figure $2 \mathrm{~B}$ ). It makes then sense to assume that a small fraction (about 1\%) of the initial excited population does not undergo ultrafast charge transfer, possibly because of a larger distance between FAD and $Y_{346}$, and therefore decays much more slowly. This interpretation agrees well with the resemblance of the corresponding anisotropy spectrum, EAAS5, with the initial one, EAAS1, which is clearly assigned to $\mathrm{FAD}_{\mathrm{ox}}{ }^{*}$. With excitation at $405 \mathrm{~nm}$, the signature of EADS5 is not so clear (Figure S6A) but the signal-to-noise ratio of this experiment is somewhat worse. In the absence of more decisive contradictory proof, we tentatively maintain our interpretation that the plateau is due to a small population of slowly decaying excited flavin.

The corrections of EADS3' and EADS4' made in Section 4.1.3 also revealed the existence of a minor population of excited flavin (fraction $\alpha$ ) that decays more slowly than the main part. This additional population is actually distinct from the one of the plateau because EADS5 was subtracted from all other EADS (Equation 3) before the correction. Since the global fit could not separate it from the components assigned to charge recombination, and as $\alpha$ substantially decreases from EADS3' to EADS4', it may be inferred that this minor population likely decays in a few ps, instead of 0.43 ps for the main decay. It therefore appears that a distribution of FAD species coexists, characterized by different excited-state lifetimes. This may be related to a some moderate flexibility of the active site of BsTrmFO, evoking (without reaching the same large extent) the conformal heterogeneity of the aforementioned thymidylate synthase ThyX. ${ }^{31}$ ThyX indeed exhibits a wide distribution of the distance between $F A D$ and a nearby tyrosine residue $\left(\mathrm{Y}_{91}\right)$, resulting in a highly multiphasic fluorescence decay.

\subsection{Ultrafast dynamics of WT}

As mentioned above, the ultrafast dynamics of WT is quite similar to that C53A, the first three time constants (Table 1) and DADS (Figure S3) being close. The same conclusions drawn above for C53A relative to sub-ps charge separation, coupled to excited-state relaxation, and subsequent ps charge recombination are thus still fully applicable to WT.

It is however clear from the anisotropy data that the contribution of $\mathrm{FAD}_{\mathrm{ox}}{ }^{*}$ to EAAS3 (negative dip in the SE region) is much larger for WT than for C53A (Figure S8). A correction such as the one made for C53A (Section 4.1.3) may also be performed but with a much larger fraction of $\operatorname{FAD}_{\text {ox }}{ }^{*}(\sim 25 \%$; not shown). At the next kinetic step, the weight of the $\mathrm{FAD}_{\mathrm{ox}}{ }^{*}$ population becomes so large that EADS4 can no longer be associated to charge recombination. It is rather assigned to the decay of some 
$\mathrm{FAD}_{\mathrm{ox}}{ }^{*}$ population, in $43 \mathrm{ps}$. The same assignment is further done for EADS5 (700 ps) and EADS6 (plateau). The presence of this multiplicity of $\mathrm{FAD}_{\text {ox }}{ }^{*}$ populations, decaying with different lifetimes, indicates that the heterogeneity of WT is significantly more pronounced than that of C53A. It cannot even be excluded that the actual distribution of $\mathrm{FAD}_{\mathrm{ox}}{ }^{*}$ populations is in fact continuous, with major peaks as defined by our discrete multiexponential analysis. This result agrees with our previous structural biophysical studies of BsTrmFO showing that the wild-type protein is indeed more flexible that the C53A mutant, ${ }^{7,11}$ probably because the active site cysteine plays an important role in the dynamics of the active site loop in the vicinity of FAD. This flexibility of the active site loop is likely required to allow the nucleophilic attack of the catalytic intermediate $\mathrm{FAD}=\mathrm{CH}_{2}$ by $\mathrm{C}_{53}$ in the absence of tRNA. Let us note that the "slow" $F A D_{o x}{ }^{*}$ species are only revealed by the decay of a $F A D_{o x}{ }^{*}$ difference spectrum. The nature of this decay is in fact not apparent as no intermediate, such as a $\mathrm{FAD}^{\bullet-} / \mathrm{YOH}^{\bullet+}$, is evidenced. One may just assume that the same quenching mechanism, involving reduction of the excited flavin by $Y_{346}$ followed by charge recombination, is at work in all case but the rates are modulated by the variations of distance between FAD and $\mathrm{Y}_{346}$. The absence of any visible reaction intermediate suggests that charge recombination somehow becomes faster that charge separation for the slow species.

\subsection{Multiexponential decay of the $Y_{346}$ mutants}

The following discussion is centered on the Y346A mutant of BsTrmFO but, since the transient absorption behaviors of Y346M and Y346F are very similar to that of Y346A (Section 3.3), the conclusions drawn below are applicable to all three $\mathrm{Y}_{346}$ mutants.

\subsubsection{Nature of the deactivation channel}

We have seen that the Y346A mutation inhibits the major, ultrafast, quenching pathway of BsTrmFO by photoinduced ET from $Y_{346}$ to the flavin. As previously observed for $T t T_{r m F O}{ }^{19}$ the replacement of $Y_{346}$ by a redox inert residue however does not cancel all deactivation channels. Instead of observing a very slow decay in the ns range, as expected for FAD in extended configuration $^{3,39,70}$ or riboflavin, ${ }^{49}$ a multiphasic decay including components as short as $4 \mathrm{ps}$ is observed for all $Y_{346}$ mutants we studied (Table 1). A similar behavior was reported for the TtTrmFO $\mathrm{C} 51 \mathrm{~A} / \mathrm{Y} 343 \mathrm{~F}$ double mutant. ${ }^{19}$ This fact reveals the existence of additional deactivation channels, not involving $Y_{346}$. It should additionally be mentioned that the decay of the $Y_{346}$ mutants is obviously coupled to a relaxation of the excited state, revealed by the conspicuous red shift of the SE band (Figure 3).

Like in the case of the initial flavin reduction of C53A (Section 4.1.1), we tried to separate the two phenomena by tracking the spectral position and the intensity of the maximum of the SE band as a 
function of time. Both curves (Figure S10 in ESI, Section S8) needed a sum of three exponentials to be properly fitted. The time constants obtained for the shift dynamics: are: 3, 30 and 350 ps with similar amplitudes (see Table S2). The amplitude decay is characterized by time constants of 21, 240 and 2180 ps (with relative amplitudes of $6 \%, 22 \%$ and $72 \%$, respectively). This analysis shows that the short time constant of the global analysis (4 ps) is in fact related to the shift dynamics while the long time constant (1600 ps) is essentially due to the amplitude dynamics, hence to the decay of the excited-state population.

Two hypotheses may be considered to explain the behavior of Y346A. It could first be speculated that the substitution of $\mathrm{Y}_{346}$ by other residues disrupts the stacking interaction with the isoalloxazine ring and allows this moiety to move more freely and adopt different configurations. It is on the other hand known that the excited-state lifetime of $F A D_{o x}$ in solution highly depends on the distance between the isoalloxazine and adenine moieties, with a fast decay (5-9 ps; attributed to isoalloxazine-to-adenine electron transfer) in stacked form and a slow decay (2-3 ns) in extended form..$^{3,39,70,71}$ The present multiphasic population decay could then be related to the existence of a distribution of the isoalloxazine-adenine distance in the ground state, before excitation. The shorter distances (stacked-like configurations) could for instance be responsible for the fastest decay component ( 21 ps). It may be rather safely ruled out that a movement of the isoalloxazine takes place during the decay, e.g. increasing the distance and favoring slower decays, because the transient anisotropy measured in the TA, GSB and SE bands remain nearly constant during most of the process (Figure $\mathrm{S} 8 \mathrm{C}$ ). The hypothesis of a ground-state distribution of isoalloxazine-adenine distance might additionally explain the quite slow SE shift dynamics if the different populations had different local environments (more or less exposed to water molecules of the buffer) and thus different positions of their SE band.

Alternatively, it may be hypothesized that secondary electron donors would be responsible of additional deactivation channels by ET. In the same context, Nag et al. ${ }^{19}$ considered for TtTrmFO the role of $W_{214}$, located on a flexible loop close to the flavin. The flexibility of this loop was suggested to explain the multiphasic decay, as in the case of ThyX. ${ }^{31}$ However, $\mathrm{W}_{214}$ is not conserved in BsTrmFO and the closest electron donor is $W_{286}$, situated on a $\alpha$-helix at $8.2 \AA$ from the isoalloxazine moiety of FAD (see Figure S1). Again for illustrative purpose, we estimated the impact of this rather large distance, the ET rate $\left(k_{\mathrm{ET}}\right)$ with Page et al.'s formula, here reproduced: ${ }^{52}$

$$
\log \mathrm{k}_{\mathrm{ET}}=13.0-(1.2-0.8 \rho)(R-3.6)-3.1\left(\Delta G^{0}+\lambda\right)^{2} / \lambda
$$

Using $R=8.2 \AA, \Delta G^{0}=-0.7 \mathrm{eV}$ (typical reduction potentials of excited $\mathrm{FAD}_{\text {ox }}$ and tryptophan in a photolyase were taken from Ref. $^{35}$ ), $\lambda=1 \mathrm{eV}$ and $\rho=0.76$ (standard values taken from Ref. ${ }^{52}$ ), Equation 7 yields a time constant of the order of 100 ps. It is thus possible that $W_{286}$ would be responsible for the intermediate decay time (240 ps). It is more difficult to explain the 21-ps decay 
with the same cause because $W_{286}$ is not located in a particularly flexible position and large variations of its distance to FAD are unlikely. It is also hard to conceive that this deactivation channel would not drain completely the excited-state population and leave a large fraction of it decaying in the ns regime (2180 ps).

For the reasons just exposed, we tentatively favor the first hypothesis, based on a static distribution of the isoalloxazine-adenine distance after disruption of the stacking with $\mathrm{Y}_{346}$. This interpretation would in turn confirm that $\mathrm{Y}_{346}$ plays a crucial role to anchor FAD in the extended configuration, and keeps it in a suitable position to perform its role in the enzymatic activity of TrmFO, as previously discussed. ${ }^{14}$ We however do not rule out the possibility that ET from $W_{286}$ to the excited flavin could also contribute to the decay of Y346A. A specific follow-up study on the Y346A/W386F double mutant (scheduled in the near future) would likely decide on this specific matter.

\subsubsection{Nature of the plateau}

We finally discuss the spectral change occurring in the final kinetic phase of all $Y_{346}$ mutants. As the normalized EADS clearly show (Figure S5C), the shape of the plateau is significantly different from all preceding EADS. This is readily explained by the formation of a new photoproduct, which we propose to be the triplet state of the flavin (noted $\mathrm{FAD}_{\mathrm{ox}}^{\mathrm{T}_{1}}$ ). It is indeed known that the triplet state of flavins in solution ${ }^{72,73}$ or bound to different proteins $s^{23,72-76}$ is formed in the ns regime with relatively high quantum yields (up to 0.60 for phototropi ${ }^{73}$ ). It is however obvious that the SE band of the excited singlet of $\mathrm{FAD}_{\mathrm{ox}}$ (here noted $\mathrm{FAD}_{\mathrm{ox}}^{\mathrm{S}_{1}}$ for clarity) is still present in EADS4 (negative dip around $565 \mathrm{~nm}$ ), overlapped by a dominant positive background. We therefore propose that EADS4 is a superposition of contributions of both $\mathrm{FAD}_{\mathrm{OX}}^{\mathrm{S}_{1}}$ and $\mathrm{FAD}_{\mathrm{OX}}^{\mathrm{T}_{1}}$.

To support this hypothesis, a variable fraction of EADS3 was subtracted from EADS4 (Equation 8), so as to obtain a spectrum matching approximately the shape of published difference spectra of triplet flavin. $^{75,76}$

$$
\text { EADS4 }^{\prime}=\text { EADS4 }-\alpha \text { EADS3 }
$$

Figure 8 shows that a suitable choice of $\alpha$ makes EADS4' highly resemble published transient absorption spectra of the triplet state of different flavoproteins (phototropin from Avena sativa (LOV2 domain) ${ }^{76}$ and AppA from Rhodobacter sphaeroides (BLUF domain) ${ }^{75}$ ). EADS4' is thus assigned to $\mathrm{FAD}_{\mathrm{Ox}}^{\mathrm{T}_{1}}$. The superposition of contributions of both $\mathrm{FAD}_{\mathrm{Ox}}^{\mathrm{S}_{1}}$ and $\mathrm{FAD}_{\mathrm{Ox}}^{\mathrm{T}_{1}}$ in EADS4 means that the global fit was not capable of completely separating the slowest decay of $\mathrm{FAD}_{\mathrm{ox}}^{\mathrm{S}_{1}}$ from the rise of $\mathrm{FAD}_{\mathrm{OX}}^{\mathrm{T}_{1}}$, likely because this reaction takes place in the ns regime and our observation window is limited to $3.2 \mathrm{~ns}$. 


\section{CONCLUSION}

In the present work, we have measured the photoinduced flavin dynamics of BsTrmFO, both in wild-type and C53A proteins, by ultrafast transient absorption spectroscopy. We have shown that the selective excitation of $F A D_{0 x}$ in both cases leads to the ultrafast formation of the $F A D^{\bullet-} / Y_{346} \mathrm{OH}^{\bullet+}$ radical pair. The biexponential dynamics of this reaction (about 0.35 and $1.1 \mathrm{ps}$ in both proteins) is attributed to the coupling of the pure electron transfer reaction with the response of the local environment upon flavin excitation. Both phenomena could be separated in C53A, yielding a time constant of $0.43 \mathrm{ps}$ for the pure flavin reduction and $1.3 \mathrm{ps}$ for the excited flavin relaxation. The faster rate of ET in BsTrmFO than in TtTrmFO $\left(1.1 \mathrm{ps}^{19}\right)$ could be due to a slightly shorter distance between FAD and $Y_{346}$ in BsTrmFO (2.7 vs. 3.3 $\AA$ ). The excited flavin relaxation dynamics, which was not reported in $T t T r m F O$, is here tentatively explained by the somewhat less rigid structure of BsTrmFO as compared to TtTrmFO, which comes from a thermophile organism. The absorption spectrum of the $\mathrm{FAD}^{\bullet-} / \mathrm{Y}_{346} \mathrm{OH}^{\bullet+}$ radical pair, corrected from the ground-state bleaching contribution, is proposed (Figure 7). This radical pair decays via a charge recombination, mostly in 3-4 ps. An additional decay component of $9.3 \mathrm{ps}$ is detected in the case of C53A, possibly due to the response of the protein environment to the charge distribution of the radical pair or to vibrational cooling of the latter. Remarkably, the $\mathrm{Y}_{346} \mathrm{OH}^{\bullet+}$ radical does not deprotonate prior or during the recombination process as expected from its high acidity. We hypothesized that this is could be due to the H-bond between $\mathrm{Y}_{346}$ and the amide group of $\mathrm{C}_{53}$, which would increase the pKa of $\mathrm{Y}_{346} \mathrm{OH}^{\bullet+}$ and slow down its deprotonation. Compared to the C53A mutant, the dynamics of wild-type BsTrmFO shows additional slow decay components (43 and 700 ps, larger plateau) that are assigned to non-negligible populations of excited $\mathrm{FAD}_{\text {ox }}$ not undergoing fast photoreduction. This result agrees well with more flexible structure of WT as compared to $\mathrm{C}_{53} \mathrm{~A}$, likely due to the role played by $\mathrm{C}_{53}$ in the dynamics of the active site loop. ${ }^{7,11}$

On the other hand, three point mutants of $\mathrm{Y}_{346}$ (Y346A, Y346M and $\mathrm{Y346F}$ ) were studied, cancelling the electron donating character of this residue. The ultrafast flavin photoreduction observed in WT and $\mathrm{C} 53 \mathrm{~A}$ is here effectively inhibited but slower, secondary excited-state quenching channels are detected (4.0, 100 and 1600 ps in Y346A). No major differences are seen between the different mutants. Since BsTrmFO does not bear the $\mathrm{W}_{214}$ residue invoked to play the role of secondary electron donor in $T t \operatorname{TrmFO},{ }^{19}$ two alternative hypotheses are invoked to explain the observed decays. It may first be supposed that $W_{286}$, situated at $8.2 \AA$ from FAD, is capable of reducing the excited flavin. It is however difficult to explain how this sole residue, which lies in a non-flexible region of the protein, would account for all the decay components. Without ruling out the possibility that this 
quenching by $W_{286}$ accounts for one of the observed decays, we tentatively favor the idea that the $\mathrm{Y}_{346}$ mutations destabilize the anchoring of the isoalloxazine ring $^{14}$ and allow a relatively large conformational heterogeneity of TrmFO's active site. This would in turn create a distribution of isoalloxazine-adenine distance, the adenine moiety playing the role of quencher as in the stacked configuration of $F A D_{\text {ox }}$ in solution. ${ }^{39}$ The conformational sampling of FAD would therefore suitably explain a part of the multiexponential decay.

Overall, the first outcome of this study is a clear support for the $\pi$ - $\pi$ stacking and $\mathrm{H}$-bond coupling mechanism in the control of TrmFO's active site dynamics, required for competent orientation of the reactive centers during catalysis. Secondly, the fact that short-lived $\mathrm{FAD}^{{ }^{\circ-}} / \mathrm{YOH}^{\bullet+}$ photoproduct is stabilized by both mesophilic and thermophilic orthologous enzymes indicates that this photochemical property is an inherent peculiarity of TrmFO's active site making this family of flavoprotein a suitable model for future investigations of $\mathrm{YOH}^{\bullet+}$ reactivity. 


\section{Tables and Figures}

Table 1. Time constants of the global multiexponential fit of the transient absorption spectra of the five studied variants of BsTrmFO (WT, C53A, Y346A, Y346M and Y346F), obtained upon excitation at $475 \mathrm{~nm}$. Fit errors $(\sigma)$ are indicated after the \pm sign. The coefficient of determination $\left(R^{2}\right)$ characterizing the quality of the fit is given in the last column.

\begin{tabular}{lllllll}
\hline Variant & $\tau_{1}(p s)$ & $\tau_{2}(p s)$ & $\tau_{3}(p s)$ & $\tau_{4}(p s)$ & $\tau_{5}(p s)$ & $R^{2}$ \\
\hline WT & $0.38 \pm 0.03$ & $1.15 \pm 0.1$ & $4.1 \pm 0.3$ & $43 \pm 8$ & $700 \pm 50$ & 0.99972 \\
C53A & $0.30 \pm 0.02$ & $1.0 \pm 0.1$ & $3.0 \pm 0.3$ & $9.3 \pm 1.4$ & & 0.99986 \\
\hline Y346A & $4.0 \pm 0.3$ & $100 \pm 10$ & $1600 \pm 100$ & & 0.99971 \\
Y346M & $4.2 \pm 0.2$ & $93 \pm 6$ & $1420 \pm 50$ & & 0.99985 \\
Y346F & $3.9 \pm 0.3$ & $89 \pm 7$ & $1650 \pm 60$ & & 0.99982 \\
\hline
\end{tabular}

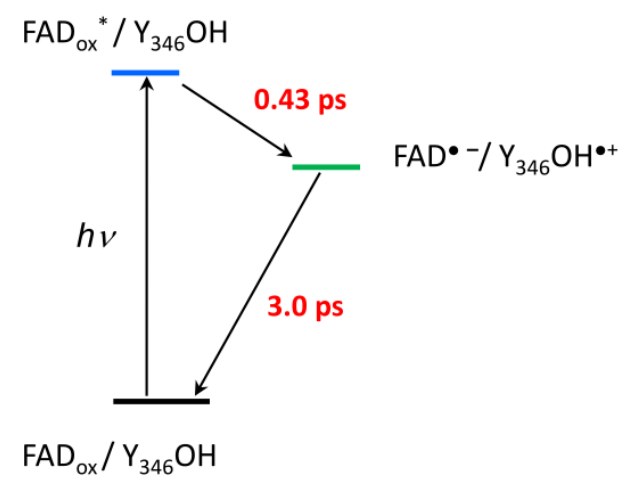

Scheme 1. Simplified reaction scheme of BsTrmFO/C53A (only the main electron transfer reactions are represented). 

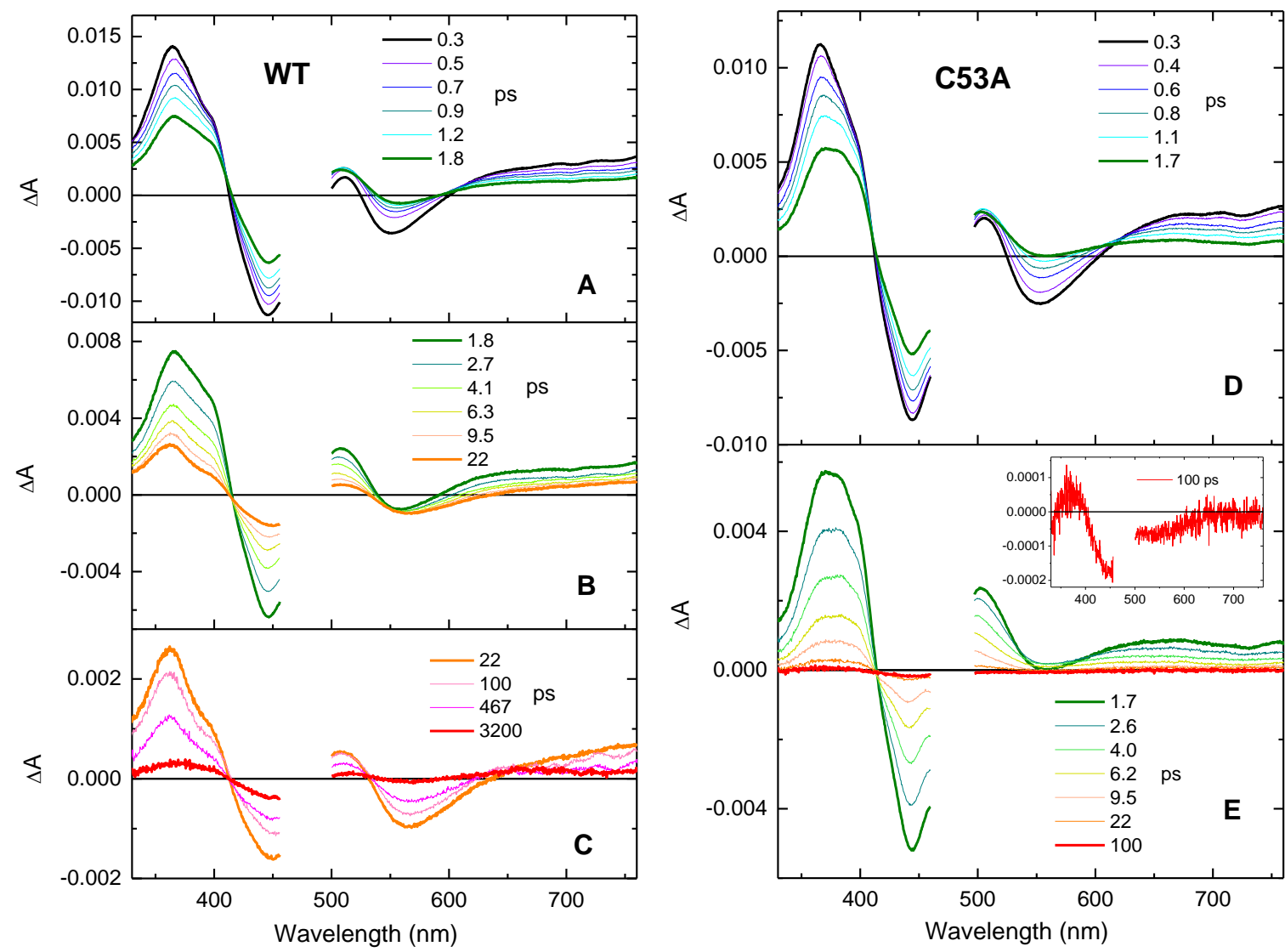

Figure 1. Isotropic transient spectra of the of wild-type BsTrmFO (A-C) and of its C53A mutant (D-E) at selected pump-probe delays, after excitation at $475 \mathrm{~nm}$. 

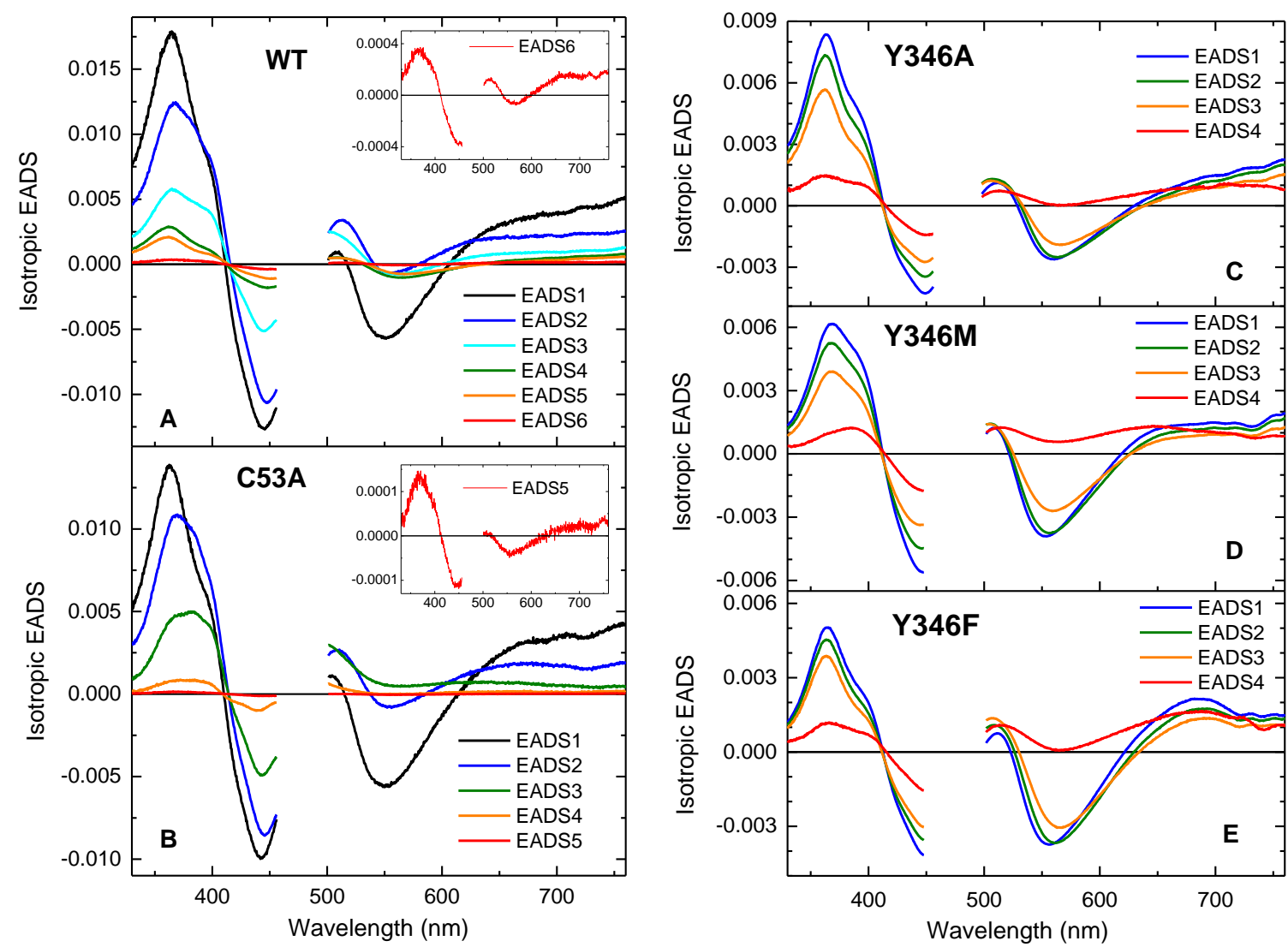

Figure 2. Isotropic EADS deduced from the global fit of the transient absorption spectra of WT (A), C53A (B), Y346A (C), Y346M (D) and Y346F (E), after excitation at $475 \mathrm{~nm}$. See corresponding time constants in Table 1.

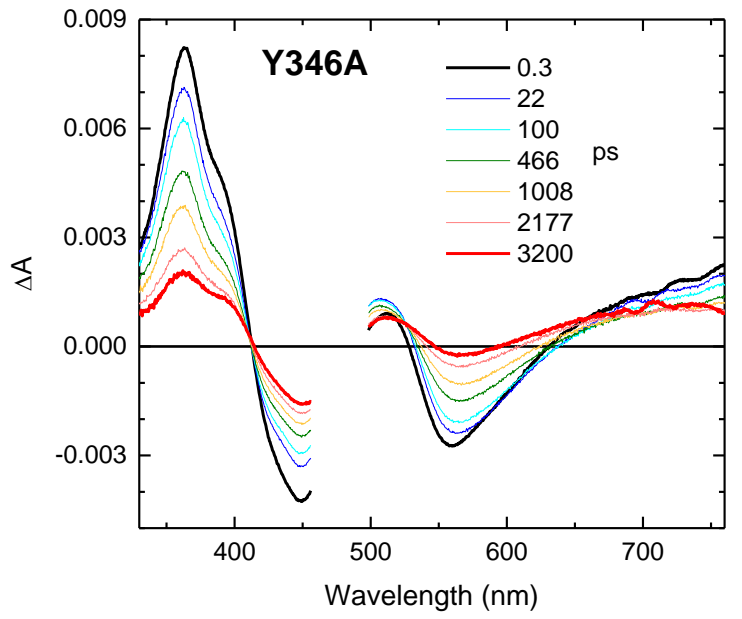

Figure 3. Isotropic transient spectra of the Y346A mutant of BsTrmFO at selected pump-probe delays, after excitation at $475 \mathrm{~nm}$. 


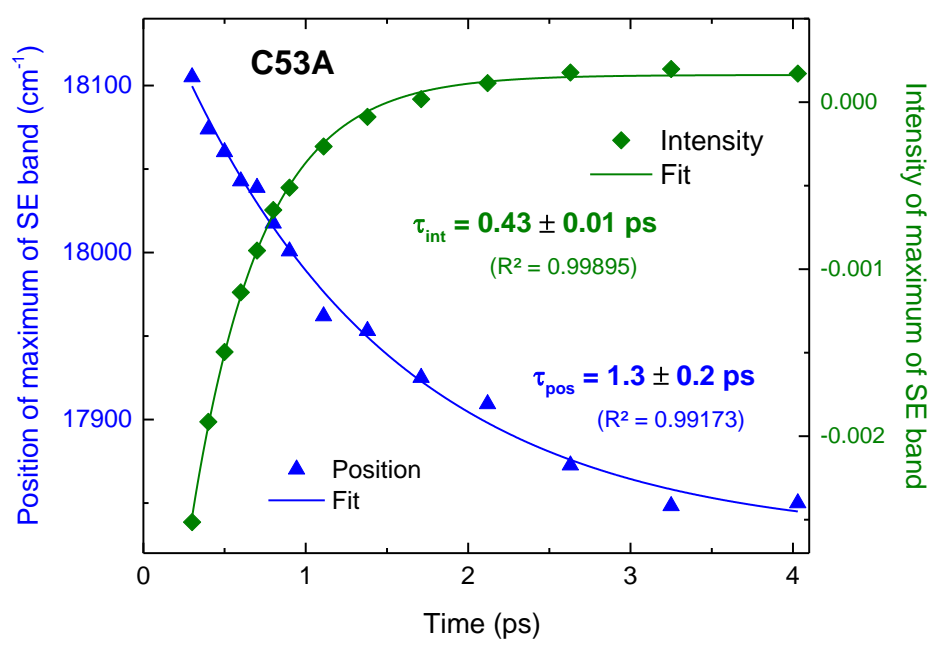

Figure 4. Tracking of the spectral position (left y-axis) and the intensity (right $y$-axis) of the maximum of the SE band of C53A, after excitation at $475 \mathrm{~nm}$, as a function of time. To increase the precision of the readings, the SE bands were first locally fitted by exponentially modified Gaussians. The data points were then independently fitted by a single exponential decay $\left(y=y_{0}+a e^{-t / \tau}\right)$.

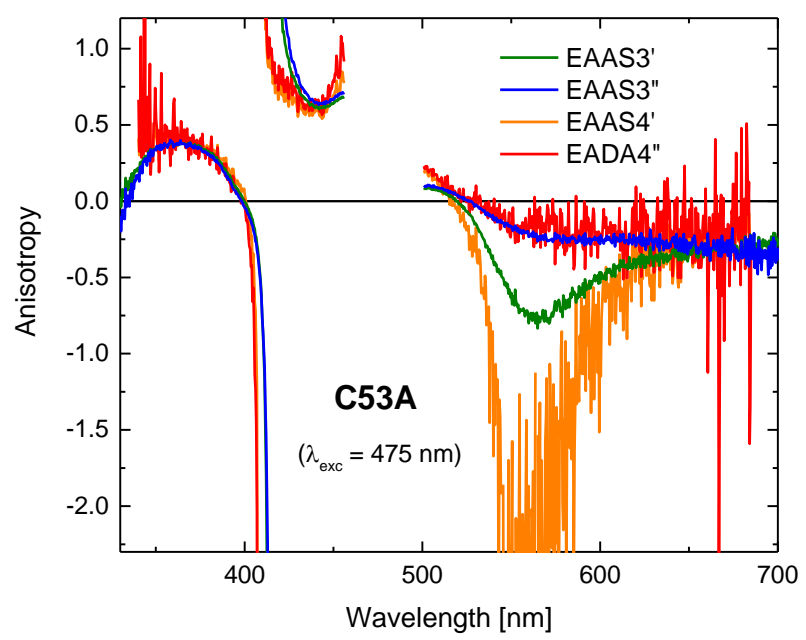

Figure 5. Correction of EAAS3 and EAAS4 in the case of C53A with excitation at $475 \mathrm{~nm}$. EAAS' are the anisotropy spectra deduced from the polarized EADS' (Equation 3); EAAS" are further deduced from EADS" (Equation 4). 


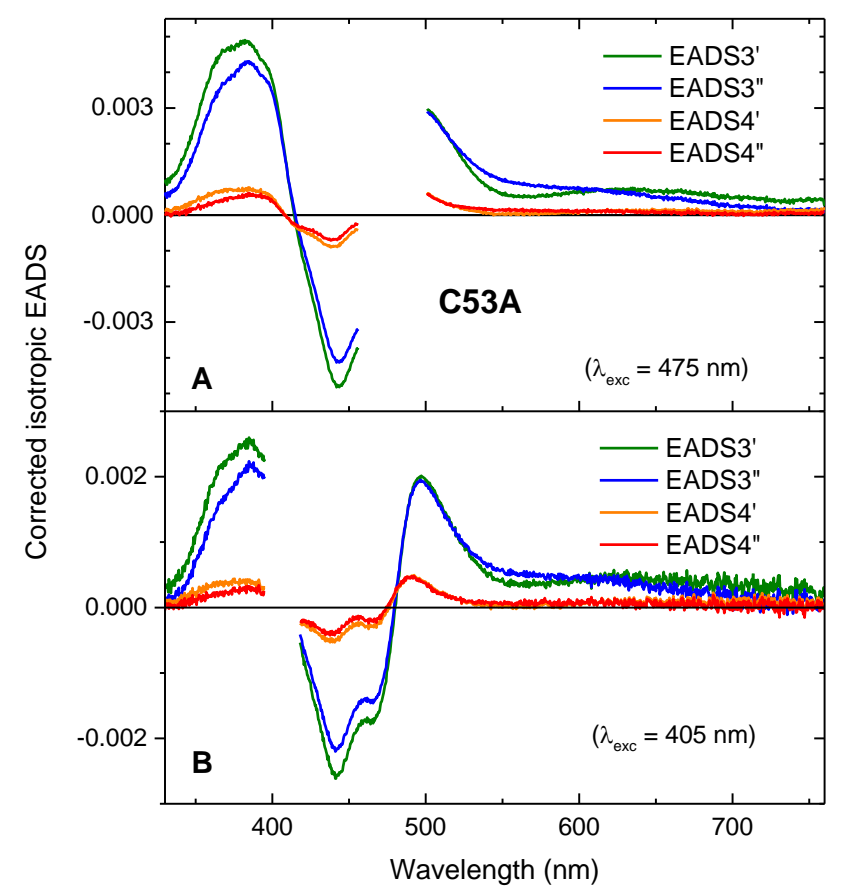

Figure 6. Correction of EADS3 and EADS4 in the case of C53A with excitation at $475 \mathrm{~nm}(\mathrm{~A})$ and 405 $\mathrm{nm}$ (B). EADS' and EADS" are deduced from Equations 3 and 4 with the same choice of $\alpha$ parameters as in Figure 5.

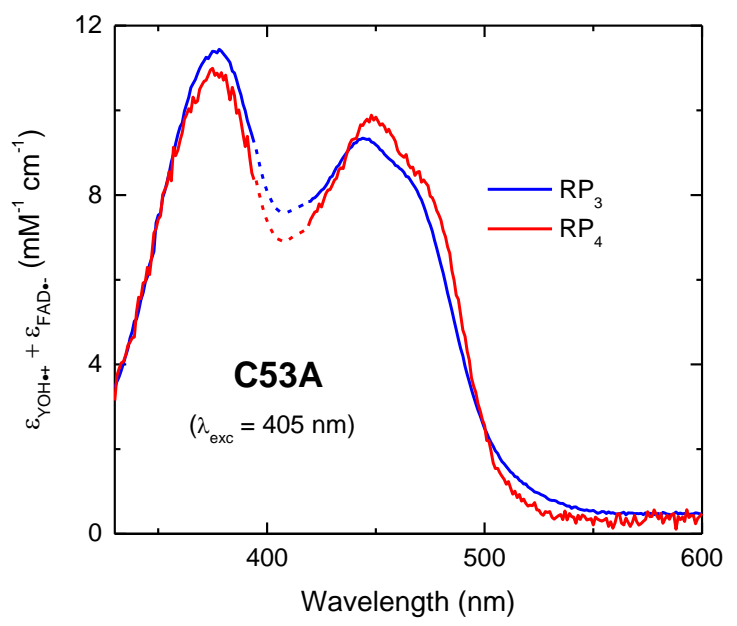

Figure 7. Molar absorption coefficient spectrum of the $\mathrm{FAD}^{\bullet-} / \mathrm{Y}_{346} \mathrm{OH}^{\bullet+}$ radical pair, as extracted with Equation 6 from EADS3" $\left(\mathrm{RP}_{3}\right)$ and from EADS4" $\left(\mathrm{RP}_{4}\right)$ of $\mathrm{C} 53 \mathrm{~A}$ with excitation at $405 \mathrm{~nm}$. The region in dotted line corresponds to linearly interpolated EADS" in the masked region of pump scattering. 


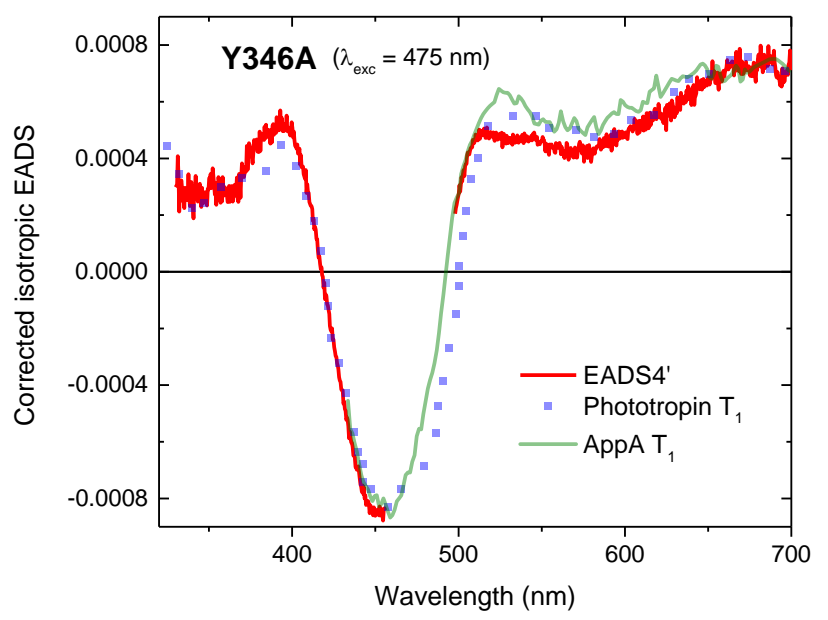

Figure 8. Correction of EADS4 in the case of Y346A with excitation at $475 \mathrm{~nm}$. EADS'4 (red line) is deduced from Equation 8: $\alpha$ was chosen so as to let EADS4' resemble the transient absorption spectra of the triplet state of the phototropin from Avena sativa (LOV2 domain) ${ }^{76}$ (blue squares) and AppA from Rhodobacter sphaeroides (BLUF domain) $)^{75}$ (green line).

\section{CONFLICT OF INTERESTS}

There are no conflicts to declare.

\section{ACKNOWLEDGEMENTS}

This work was supported by French State Program "Investissements d'Avenir" (ANR-15-CE11-000401).

\section{REFERENCES}

1. C. T. Walsh and T. A. Wencewicz, Nat. Prod. Rep., 2013, 30, 175-200.

2. V. Piano, B. A. Palfey and A. Mattevi, Trends Biochem. Sci., 2017, 42, 457-469.

3. Y. T. Kao, C. Saxena, T. F. He, L. J. Guo, L. J. Wang, A. Sancar and D. P. Zhong, J. Am. Chem. Soc., 2008, 130, 13132-13139.

4. V. Nandwana, I. Samuel, G. Cooke and V. M. Rotello, Acc. Chem. Res., 2013, 46, 1000-1009.

5. L. Fruk, C.-H. Kuo, E. Torres and C. M. Niemeyer, Angew. Chem. Int. Ed., 2009, 48, 1550-1574.

6. J. Urbonavicius, S. Skouloubris, H. Myllykallio and H. Grosjean, Nucleic Acids Res., 2005, 33, 3955-3964.

7. H. Nishimasu, R. Ishitani, K. Yamashita, C. Iwashita, A. Hirata, H. Hori and O. Nureki, Proc. Natl. Acad. Sci. USA, 2009, 106, 8180-8185.

8. R. Yamagami, K. Yamashita, H. Nishimasu, C. Tomikawa, A. Ochi, C. Iwashita, A. Hirata, R. Ishitani, O. Nureki and H. Hori, J. Biol. Chem., 2012, 287, 42480-42494.

9. D. Hamdane, H. Grosjean and M. Fontecave, J. Mol. Biol., 2016, 428, 4867-4881.

10. D. Hamdane, V. Guerineau, S. Un and B. Golinelli-Pimpaneau, Biochemistry, 2011, 50, 52085219. 
11. D. Hamdane, M. Argentini, D. Cornu, H. Myllykallio, S. Skouloubris, G. Hui-Bon-Hoa and B. Golinelli-Pimpaneau, J. Biol. Chem., 2011, 286, 36268-36280.

12. D. Hamdane, M. Argentini, D. Cornu, B. Golinelli-Pimpaneau and M. Fontecave, J. Am. Chem. Soc., 2012, 134, 19739-19745.

13. D. Hamdane, E. Bruch, S. Un, M. Field and M. Fontecave, Biochemistry, 2013, 52, 8949-8956.

14. D. Hamdane, C. Bou-Nader, D. Cornu, G. Hui-Bon-Hoa and M. Fontecave, Biochemistry, 2015, 54, 4354-4364.

15. H. Hori, Front. Gen., 2014, 5.

16. C. Bou-Nader, D. Cornu, V. Guerineau, T. Fogeron, M. Fontecave and D. Hamdane, Angew. Chem. Int. Ed., 2017, 56, 12523-12527.

17. T. V. Mishanina, L. Yu, K. Karunaratne, D. Mondal, J. M. Corcoran, M. A. Choi and A. Kohen, Science, 2016, 351, 507-510.

18. H. Myllykallio, P. Sournia, A. Heliou and U. Liebl, Front. Microbiol., 2018, 9.

19. L. Nag, P. Sournia, H. Myllykallio, U. Liebl and M. H. Vos, J. Am. Chem. Soc., 2017, 139, 1150011505.

20. N. Mataga, H. Chosrowjan, Y. Shibata, F. Tanaka, Y. Nishina and K. Shiga, J. Phys. Chem. B, 2000, 104, 10667-10677.

21. D. P. Zhong and A. H. Zewail, Proc. Natl. Acad. Sci. USA, 2001, 98, 11867-11872.

22. N. Mataga, H. Chosrowjan, S. Taniguchi, F. Tanaka, N. Kido and M. Kitamura, J. Phys. Chem. B, 2002, 106, 8917-8920.

23. M. Gauden, J. S. Grinstead, W. Laan, I. H. M. van Stokkum, M. Avila-Perez, K. C. Toh, R. Boelens, R. Kaptein, R. van Grondelle, K. J. Hellingwerf and J. T. M. Kennis, Biochemistry, 2007, 46, 74057415.

24. Y. T. Kao, C. Tan, S. H. Song, N. Ozturk, J. Li, L. J. Wang, A. Sancar and D. P. Zhong, J. Am. Chem. Soc., 2008, 130, 7695-7701.

25. K. Brettel and M. Byrdin, Curr. Opin. Struct. Biol., 2010, 20, 693-701.

26. D. Immeln, A. Weigel, T. Kottke and J. L. Perez Lustres, J. Am. Chem. Soc., 2012, 134, 1253612546.

27. K. Lugsanangarm, S. Pianwanit, A. Nueangaudom, S. Kokpol, F. Tanaka, N. Nunthaboot, K. Ogino, R. Takagi, T. Nakanishi, M. Kitamura, S. Taniguchi and H. Chosrowjan, J. Photochem. Photobiol. A, 2013, 268, 58-66.

28. F. Tanaka, K. Lugsanangarm, N. Nunthaboot, A. Nueangaudom, S. Pianwanit, S. Kokpol, S. Taniguchi and H. Chosrowjan, Phys. Chem. Chem. Phys., 2015, 17, 16813-16825.

29. K. Lugsanangarm, A. Nueangaudom, S. Kokpol, S. Pianwanit, N. Nunthaboot, F. Tanaka, S. Taniguchi and H. Chosrowjan, J. Photochem. Photobiol. A, 2015, 306, 66-79.

30. N. Nunthaboot, K. Lugsanangarm, A. Nueangaudom, S. Pianwanit, S. Kokpol, F. Tanaka, S. Taniguchi, H. Chosrowjan, T. Nakanishi and M. Kitamura, J. Photochem. Photobiol. A, 2016, 326, 60-68.

31. S. P. Laptenok, L. Bouzhir-Sima, J.-C. Lambry, H. Myllykallio, U. Liebl and M. H. Vos, Proc. Natl. Acad. Sci. USA, 2013, 110, 8924-8929.

32. W. T. Dixon and D. Murphy, J. Chem. Soc. Faraday Trans. II, 1976, 72, 1221-1230.

33. K. Lugsanangarm, S. Pianwanit, S. Kokpol, F. Tanaka, H. Chosrowjan, S. Taniguchi and N. Mataga, J. Photochem. Photobiol. A, 2011, 219, 32-41.

34. J. Pan, M. Byrdin, C. Aubert, A. P. M. Eker, K. Brettel and M. H. Vos, J. Phys. Chem. B, 2004, 108, 10160-10167.

35. Z. Y. Liu, C. Tan, X. M. Guo, J. Li, L. J. Wang, A. Sancar and D. P. Zhong, Proc. Natl. Acad. Sci. USA, 2013, 110, 12966-12971.

36. R. Martin, F. Lacombat, A. Espagne, N. Dozova, P. Plaza, J. Yamamoto, P. Muller, K. Brettel and A. de la Lande, Phys. Chem. Chem. Phys., 2017, 19, 24493-24504.

37. D. Hamdane, S. Skouloubris, H. Myllykallio and B. Golinelli-Pimpaneau, Protein Expr. Purif., 2010, 73, 83-89.

38. R. J. Stanley and H. Jang, J. Phys. Chem. A, 1999, 103, 8976-8984. 
39. J. Brazard, A. Usman, F. Lacombat, C. Ley, M. M. Martin and P. Plaza, J. Phys. Chem. A, 2011, 115, 3251-3262.

40. J. Brazard, A. Usman, F. Lacombat, C. Ley, M. M. Martin, P. Plaza, L. Mony, M. Heijde, G. Zabulon and C. Bowler, J. Am. Chem. Soc., 2010, 132, 4935-4945.

41. A. Yoshimura, M. Z. Hoffman and H. Sun, J. Photochem. Photobiol. A, 1993, 70, 29-33.

42. M. Byrdin, V. Thiagarajan, S. Villette, A. Espagne and K. Brettel, Rev. Sci. Instr., 2009, 80, 043102.

43. K. Ekvall, P. van der Meulen, C. Dhollande, L. E. Berg, S. Pommeret, R. Naskrecki and J. C. Mialocq, J. Appl. Phys., 2000, 87, 2340-2352.

44. M. Byrdin, S. Villette, A. Espagne, A. P. M. Eker and K. Brettel, J. Phys. Chem. B, 2008, 112, 6866-6871.

45. E. R. Henry and J. Hofrichter, Methods Enzymol., 1992, 210, 129-193.

46. I. H. M. van Stokkum, S. L. Delmar and R. van Grondelle, Biochim. Biophys. Acta Bioenerg., 2004, 1657, 82-104.

47. M. Gauden, I. H. M. van Stokkum, J. M. Key, D. C. Luehrs, R. Van Grondelle, P. Hegemann and J. T. M. Kennis, Proc. Natl. Acad. Sci. USA, 2006, 103, 10895-10900.

48. J. P. Hoben, C. E. Lubner, M. W. Ratzloff, G. J. Schut, D. M. N. Nguyen, K. W. Hempel, M. W. W. Adams, P. W. King and A.-F. Miller, J. Biol. Chem., 2017, 292, 14039-14049.

49. A. Weigel, A. Dobryakov, B. Klaumuenzer, M. Sajadi, P. Saalfrank and N. P. Ernsting, J. Phys. Chem. B, 2011, 115, 3656-3680.

50. F. Lacombat, A. Espagne, N. Dozova, P. Plaza, E. Ignatz, S. Kiontke and L.-O. Essen, Phys. Chem. Chem. Phys., 2018, 20, 25446-25457.

51. R. A. Marcus and N. Sutin, Biochim. Biophys. Acta, 1985, 811, 265-322.

52. C. C. Page, C. C. Moser, X. X. Chen and P. L. Dutton, Nature, 1999, 402, 47-52.

53. C. Aubert, P. Mathis, A. P. M. Eker and K. Brettel, Proc. Natl. Acad. Sci. USA, 1999, 96, 54235427.

54. B. Giese, M. Wang, J. Gao, M. Stoltz, P. Müller and M. Graber, J. Org. Chem., 2009, 74, 36213625.

55. D. Nohr, S. Franz, R. Rodriguez, B. Paulus, L. O. Essen, S. Weber and E. Schleicher, Biophys. J., 2016, 111, 301-311.

56. P. Changenet-Barret, C. T. Choma, E. F. Gooding, W. F. DeGrado and R. M. Hochstrasser, J. Phys. Chem. B, 2000, 104, 9322-9329.

57. S. K. Pal, J. Peon and A. H. Zewail, Proc. Natl. Acad. Sci. USA, 2002, 99, 1763-1768.

58. C.-W. Chang, T.-F. He, L. Guo, J. A. Stevens, T. Li, L. Wang and D. Zhong, J. Am. Chem. Soc., 2010, 132, 12741-12747.

59. S. Mondal, S. Mukherjee and B. Bagchi, J. Chem. Phys., 2017, 147, 11.

60. A. Szilagyi and P. Zavodszky, Structure, 2000, 8, 493-504.

61. F. Tanaka, H. Chosrowjan, S. Taniguchi, N. Mataga, K. Sato, Y. Nishina and K. Shiga, J. Phys. Chem. B, 2007, 111, 5694-5699.

62. M. Kundu, T.-F. He, Y. Lu, L. Wang and D. Zhong, J. Phys. Chem. Lett., 2018, 9, 2782-2790.

63. F. Lacombat, P. Plaza, M. A. Plamont and A. Espagne, J. Phys. Chem. Lett., 2017, 8, 1489-1495.

64. V. Massey and G. Palmer, Biochemistry, 1966, 5, 3181-3189.

65. B. Liu, H. Liu, D. Zhong and C. Lin, Curr. Opin. Plant Biol., 2010, 13, 578-586.

66. A. Berndt, T. Kottke, H. Breitkreuz, R. Dvorsky, S. Hennig, M. Alexander and E. Wolf, J. Biol. Chem., 2007, 282, 13011-13021.

67. V. E. Zubarev and O. Brede, Acta Chem. Scand., 1997, 51, 224-228.

68. K. Kesper, F. Diehl, J. G. G. Simon, H. Specht and A. Schweig, Chem. Phys., 1991, 153, 511-517.

69. T. A. Gadosy, D. Shukla and L. J. Johnston, J. Phys. Chem. A, 1999, 103, 8834-8839.

70. P. A. W. van den Berg, K. A. Feenstra, A. E. Mark, H. J. C. Berendsen and A. Visser, J. Phys. Chem. B, 2002, 106, 8858-8869.

71. H. Chosrowjan, S. Taniguchi, N. Mataga, F. Tanaka and A. Visser, Chem. Phys. Lett., 2003, 378, 354-358. 
72. A. Penzkofer, L. Endres, T. Schiereis and P. Hegemann, Chem. Phys., 2005, 316, 185-194.

73. J. T. M. Kennis, S. Crosson, M. Gauden, I. H. M. van Stokkum, K. Moffat and R. van Grondelle, Biochemistry, 2003, 42, 3385-3392.

74. A. Losi, E. Polverini, B. Quest and W. Gärtner, Biophys. J., 2002, 82, 2627-2634.

75. M. Gauden, S. Yeremenko, W. Laan, I. H. M. van Stokkum, J. A. Ihalainen, R. van Grondelle, K. J. Hellingwerf and J. T. M. Kennis, Biochemistry, 2005, 44, 3653-3662.

76. T. E. Swartz, S. B. Corchnoy, J. M. Christie, J. W. Lewis, I. Szundi, W. R. Briggs and R. A. Bogomolni, J. Biol. Chem., 2001, 276, 36493-36500. 